\title{
NBSIR 75-931
}

\section{The National Measurement System for Pressure}

Peter L.M. Heydemann

Institute for Basic Standards

National Bureau of Standards

Washington, D.C. 20234

September 1976

QC

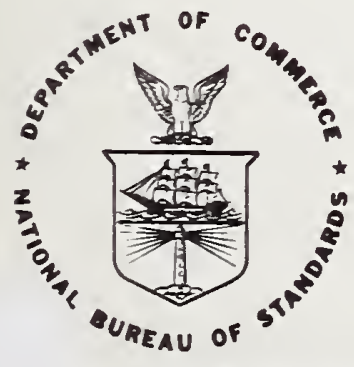

100

3. DEPARTMENT OF COMMERCE

.456

IONAL BUREAU OF STANDARDS

* 75.931

1976 

NBSIR 75-931

\section{THE NATIONAL MEASUREMENT SYSTEM FOR PRESSURE}

Peter L.M. Heydemann

Institute for Basic Standards

National Bureau of Standards

Washington, D.C. 20234

September 1976

U.S. DEPARTMENT OF COMMERCE, Elliot L. Richardson, Secretary Edward O. Vetter, Under Secretary

Dr. Betsy Ancker-Johnson, Assistant Secretary for Science and Technology

NATIONAL BUAEAU OF STANDARDS. Emest Ambler, Acting Director 



\title{
DIVISION SUMMARY REPORT
}

\author{
A Study of \\ THE NATIONAL MEASUREMENT SYSTEM FOR PRESSURE
}

Peter L.M. Heydemann

Heat Division

\section{EXECUTIVE SUMMARY}

The field of this study is the measurement of pressure and vacuum. This field has developed from humble beginnings in the laboratory of Evangelista Torricel1i in 1644 to one that encompasses practically al1 manufacturing processes, the operation of many types of machines, important scientific endeavors and our daily life. Industrial applications cover 17 decades of pressure and science adds another five. Within its range are billion-dollar industries using pressure or vacuum in a significant way to make or control semiconductors, radiators, beer cans, aircraft, automobile tires, missiles, freeze dried food, power plants and many other products or manufacturing activities. Savings of great economic significance can be achieved through accurate measurements of pressure. The safety of aircraft and of nuclear reactors is ensured through, among others, pressure measurements.

A significant part of the measurements in this system are referred to NBS primary standards mainly through the instrumentation industry. NBS calibration services now cover about five decades of pressure and an expansion to seven decades is planned for the near future. The calibration services are based on a number of primary standards, whose accuracy and precision are adequate for most purposes and work continues to update and improve these standards. The dissemination of accurate measurements into the field is not always satisfactory. Large uncertainties added in the calibration chains are due to inadequate technical and mathematical procedures, lack of good transfer standards and lack of training of the personnel involved. The calibration services are backed up by training of industrial personnel, preparation of technical manuals and reports, data evaluation service, laboratory evaluation service and extensive consultations. All of these back-up services were prompted by early results from this investigation.

The field of pressure measurements is currently undergoing rapid changes through the introduction of new types of measuring instruments, through an expansion of the range of pressures used in industry and through the requirement for lower uncertainties. There is close cooperation between NBS and the professional and engineering societies on the development of the necessary measurement standards and test codes. Increased awareness of possible safety problems with gages and transducers, and particularly with high pressure vessels was prompted by the Occupational Safety and Health Act. Here aga in NBS is cooperating with the concerned parties to provide the necessary engineering standards. A1 1 of these activities tend to lead to an infrastructure that is more strongly focused on the primary standards of pressure at NBS and the related dissemination services.

A critical need, involving the safety of people, is felt in the pressure range required for the calibration of aircraft altimeters. No central standards are presently available to ensure uniform measurements throughout this country and the rest of the world in this important range. A new standard is, however, under construction. Also, a measurement assurance program is under study to bring this area under control. ivuclear reactors require numerous pressure transducers and at least those related to safety should be referenced to central, national standards to ensure that necessary regulations can be enforced.

A Delphi technology forecase was undertaken to determine the need for vacuum measurements, which are not provided by NBS. This study is not complete, but is has provided valuable information for planning and management decision making. Of approximately 125 randomly selected members of the American Vacuum Society $68 \%$ stated that they require vacuum calibrations in the range $10^{-3}$ to 1 torr with an uncertainty of $0.1 \%$, or better, now; $42 \%$ now require vacuum measurements to better than $1 \%$ in the range $10^{-9}$ to $10^{-6}$ torr. A much larger percentage of experts in various fields of vacuum measurements foresee these needs for the immediate future. The most demanding requirements for vacuum measurements were found in the manufacture of semiconductors, in the space industry, and in the vacuum instrumentation industry for the calibration of standard leaks and the measurement of pumping speeds. 

EXECUTIVE SUMMARY

1. INTRODUCTION

2. STRUCTURE OF THE MEASUREMENT SYSTEM

2.1 Conceptual System

2.2 Basic Technical Infrastructure

\subsubsection{Documentary Specifications System}

2.2.1.1 Standardization Institutions

2.2.1.2 Survey of Documentary Standards

\subsubsection{Instrumentation System}

2.2.2.1 Measurement Tools and Techniques

2.2.2.2 The Instrumentation Industry

\subsubsection{Reference Data}

2.2.4 Reference Material

2.2.5 Science and People

2.3 Realized Measurement Capabilities

2.4 Dissemination and Enforcement Network
2.4.1 Central Standards Authorities
2.4.2 State and Local Offices of Weights and Measures
2.4.3 Standards and Testing Laboratories and Services
2.4.4 Regulatory Agencies

2.5 Organizational Input-Output Transactions Matrix

2.5.1 Analysis of Suppliers and Users

2.5.2 Highlights re Major Users

3. IMPACT, STATUS AND TRENDS OF MEASUREMENT SYSTEM

3.1 Impact of Measurements

3.1.1 Functional, Technological and Scientific Applications

3.1.2 Economic Impacts -- Costs and Benefits

3.1.3 Socia1, Human, Man-on-the-Street Impacts

3.2 Status and Trends of the System

4. SURVEY OF NBS SERVICES

4.1 The Past

4.2 The Present -- Scope of NBS Services

4.2.1 Description of NBS Services

4.2.2 Users of NBS Services

4.2.3 A7ternate Sources

4.2.4 Funding Sources for NBS Services

4.2.5 Mechanism for Supplying Services

4.3 Impact of NBS Services

4.3.1 Economic Impact of Major User Classes

4.3.2 Technological Impact of Services

4.3.3 Pay-Off from Changes in NBS Services

4.4 Evaluation of NBS Program

4.5 The Future

5. SUMMARY AND CONCLUSIONS

Appendix A. Methodology of the Study

Appendix B. Summary of Background Documents

References 


\section{LIST OF FIGURES}

Figure 1. Piston gage, schematic

Figure 2. Controlled Clearance piston gage, schematic

Figure 3. Infrared Laser Interferometer Manometer, schematic

Figure 4. Calibration Chain

Figure 5. NBS Calibration

Figure 6. Variation of Tire Gage Calibrations

Figure 7. Input/Output by Type

Figure 8. Input/Output by Group

Figure 9. Delphi Questionnaire

Figure 10. Instructions for Delphi Questionnaire

Figure 11. Delphi Evaluation

\section{LIST OF TABLES}

Table 1. Conversion Factors for Pressure Units

Table 2. Standards for Altitude and Pressure Measurements on Aircraft

Table 3. Tire Gage Calibration

Table 4. Density of Manometric Fluids

Table 5. Fixed Points on the Pressure Scale

Table 6. Uncertainty of Primary Pressure Standards at NBS

Table 7. Required Accuracy for Vacuum Measurements

Table 8. Commercial Calibration Laboratories

Table 9. Organizational Input-Output Transaction Matrix

Table 10. Estimated Cost of Operating a Small Secondary Pressure Standards Laboratory

Table 11. Committee Memberships

Table 12. Listing of Users of NBS Pressure and Vacuum Calibration Services

Table 13. Annual Production Volume of Some Industries Benefiting from NBS Services

Table 14. Persons Contacted During the National Measurement System Analysis 


\section{INTRODUCTION}

Few types of measurements pervade our daily life as much as the measurement of pressure. Many items in daily use depend on it: automobile engines, tires, refrigerators, furnaces and airplanes. Many industrial processes require pressure measurement and control: semiconductors, vacuum melting of steel, transportation through pipe lines, powder metaliurgy and freeze drying of foods. And yet the field of pressure measurement is not well structured.

There is neither a thermodynamic nor a practical pressure scale as is the case in the temperature measurement system; there is no agreement on transfer devices. Pressure measurements are made and used in science and industry over the range from about $10^{-10}$ to $10^{12} \mathrm{~Pa}$, that is 22 decades. No one method of pressure measurement covers more than a few decades. The problems at $10^{12} \mathrm{~Pa}$ do not have anything in common with those encountered at $10^{-10 \mathrm{~Pa}}$. Instead of one or two different units, as in length or temperature measurements, there are half a dozen or more. In many areas, as, for example, ton mano. metry, vacuum and very high pressure measurements, the field is stili in its infancy. Few texts deal with the subject. There are few, if any, professional organizations devoted entirely to this field. This lack of structure in a field that covers so very many applications makes a comprehensive investi gation a task that is beyond the expertise of a single individual. Nevertheless we shall give here an overview of the field to convey the flavor of the problems inherent in the accurate measurement of pressure and its dissemination.

It was the purpose of this study to learn as much as possible about the national measurement system of pressure, to identify deficiencies and shortcomings that could then be eliminated, and to provide sufficient information for long range planning.

Personal contact through interviews, visits, letters and telephone conversations was the main source of information. Due to the Tack of structure in the pressure measurement system, committees and other organizations proved to be of very 7 imited use as sources of information. The field of vacuum measurements was treated differently. No vacuum calibration services are presently provided by IBS and consequently there are few personal contacts. Therefore, a Delphi study

was begun to forecast the requirements of the measurement system below about $10 \mathrm{kPa}$.

The study proved to be an extremely valuable exercise. It has helped us to pinpoint shortcomings. It has changed the attitude of the staff and it has fostered manv close and continuous contacts with industry. This has increased the calibration workload to the advantage of our customers.

\section{STRUCTURE OF THE MEASUREMENT SYSTEM \\ 2.1 Conceptual System}

\section{History:}

Pressure, both hydrautic and pneumatic, was used extensively in antiquity, but we have no indication that measurements of pressure were ever attempted until the early 17 th century. At that time Galileo and his contemporaries struggled with the concept of the horror vacui in order to explain observations made in their early gas-thermometers. Evangelista Torricelli, disciple of Galileo, was the first to report an actual measurement of barometric pressure. The details of his experiments are contained in a letter to his friend Ricci. The news of the experiment spread rapidly and it was repeated and refined by many of the famous thermodynamicists of the time: Descartes, Boyle, Pascal, Guericke, Watt and so forth. Until the introduction of the high pressure steam engine by Richard Trevithick about 1800, the barometer served mainly as a surveyor's tool for the purpose of leveling. Watt and a few others used it for their measurements of the properties of steam. But the advent of the high pressure steam engine created a "national need." Within the next 50 years the manometer was perfected, the piston gage was developed, a pressure gage was invented by Mr. Schinz and then patented by Mr. Bourdon. In the next one-hundred years until about the middle of this century these instruments were refined, the aneroid barometer was invented and the foundations for the transducer industry were laid. Today we find ourselves in the midst of a rapid development of essentially electronic devices for the measurement of pressure prompted by the advent of automatic data acquisition and process control. At the same time, the range of pressures used in an industrial environment is broadening and the number of measurements is increasing.

\section{Definitions:}

Over most of the pressure range used in scientific and industrial applications pressure is homogeneous in space, hydrostatic, and independent of time. It can therefore be defined as force per unit area

$$
p=\frac{F}{A}
$$


or as energy density

$$
p=\left(\frac{\partial F}{\partial V}\right)_{T}
$$

where $F$ is the Helmholtz free energy with

$$
\begin{aligned}
F & =U-T S \\
d F & =p d V-S d T .
\end{aligned}
$$

At very low pressures, that is in the medium or high vacuum area, it would be more appropriate to use molecular concentration for the characterization of a space. But it is nevertheless customary to indicate pressures even though one rarely, if ever, measures it as such.

At high pressures, or when viscous liquids or even solids are used to transmit pressure, one has to be more specific in the definition of hydrostatic pressure. This has recently been pointed out by Decker et al. in their excellent review of high pressure calibrations, in J.Phys.Chem.Ref.Data 1,773(1972).

In order to specify precisely the terminology and describe the non-ideal features of an arbitrarily stressed system in a particular non-ideal laboratory situation, we introduce the symmetric stress tensor, $T$, which is defined at each point in space. Measurable stress over finite areas can then be calculated by averaging. We note that each component of the stress tensor, in general, depends upon position and time, $T_{j j}(r, t)$ where $r$ is the position vector. The pressure, which is also a function of position and time, is defined as the negative of the average of the three normal stress components:

$$
P(r, t)=-\frac{1}{3}\left(T_{11}+T_{22}+T_{33}\right) .
$$

The shear stresses are given by the deviatoric stress tensor

$$
T^{\prime}{ }_{i j}(r, t)=T_{i j}(r, t)-\delta_{i j} P(r, t) .
$$

We are now in a position to define unambiguously the meaning of hydrostatic pressure, which is characterized by zero deviatoric shear stress and isotropic normal stresses. Mathematically we write: $T^{\prime} j j(r, t)=0$ and $-P(r, t)=T_{11}(r, t)=T_{22}(r, t)=T_{33}(r, t)$. We note that this definition does not require static (i.e., time-independent) conditions al though time-dependent changes generally involve shear. The equations define hydrostaticity at a point. If a region of space is to be hydrostatic, each point in the yolume must satisfy the hydrostatic condition, which does not necessarily imply homogeneous ( $i . e$. , constant in space) conditions. According to the above definition of pressure, nonhomogeneity in a hydrostatic medium at equilibrium can arise only from volume (body) type forces such as gravitational, magnetic, or electric forces, which in practice are often very small compared to the applied forces. It is important to note that neither homogeneous pressure nor homogeneous stress implies hydrostaticity, but simply constancy in space.

In laboratory pressure systems the time dependence in $T_{i j}$ generally arises from a change of the system from one equilibrium state to another. In a practical manner we define equilibrium as the state, which a system approaches asymptoticaliy within a laboratory time scale. All systems under pressure will support time-dependent shear stress components with some characteristic relaxation time, $\tau$, when momentarily disturbed from the equilibrium state. In many cases, especially with gases and liquids at low pressure, $\tau$ may be a small fraction of a second and is usually (but not always) negligible compared with measuring times; while in highly viscous liquids and solids the relaxation times may be of the order of many hours or even years. In the formalism discussed one can clearly distinguish between plastic solid and viscous liquid behavior during this stress relaxation. For the liquid case, the deviatoric stress $T^{\prime}{ }_{i j}$ will in time approach a zero value, but for solids $T^{\prime} i j$ will approach some non-zero final deviatoric stress state.

The approach to equilibrium will be highly dependent upon the details of the system. In solid-media systems, stress relaxation will be very complicated. For systems containing only fluids in which the viscosity of the fluid can be assumed constant thoughout the system, the approach to equilibrium is characterized by the stress components decreasing with time approximately exponentially. Spatial pressure differences within the system will obey the expression $\Delta P \propto$ $e^{-t / \tau}$ where the characteristic time, $\tau$, is directly proportional to the viscosity of the liquid but highly dependent upon the geometry of the chamber. One of the important consequences associated with this discussion is the fact that time-dependent shear stresses are generally associated with pressure changes, and adequate time (several times $\tau$ ) must be allowed for the system to approach equilibrium before reliable measurements can be made.

To measure pressure experimentally one must measure the normal stress over a finite area. If $P$ is homogeneous over that area, as it very nearly is in a fluid chamber, the simple force per unit area relationship is valid, and pressures can be determined to high accuracy. (See the 
section on the primary pressure scale.)

Pressures determined by force per unit area in solid-media systems measure some average stress over the specified area which may differ from the true average normal stresses on the surface as well as from pressures at points inside the bulk of the chamber. In genera 1, such errors wil1 be of the order of the shear strength of the solid materials.

The errors associated with measurements of material properties under these non-hydrostatic stress conditions may be more serious than the associated error in pressure since the property measurement errors are dependent upon the stress sensitivity of the parameter being considered.

Pressure Units:

Since pressure is defined as force per unit area or energy density, the units of pressure should be rather simple to list. However, on closer inspection one realizes that there are many units in which to express force and area and that consequently there is an even larger number of combinations possible. A further complication is added by the fact that people using manometers tend to measure pressure by the height of the fluid column rather than in terms of the force generated by the weight of the column over its area at the reference level.

This adds a list of bastard units, the use of which has caused innumerable difficulties with less-wel1-trained or thoughtless personnel. These bastard units should be

stamped out. This is, of course, more easily said than done, since manometry is a field full of old traditions, having developed since 1644 or about 200 years earlier than the piston gage.

The official unit of pressure in the Systeme Internationale (S.I.) is the Newton/ square meter or $\mathrm{N} / \mathrm{m}^{2}$. This unit also carries the name Pascal $(\mathrm{Pa})$ after the well known French scientist, who sent his brother-in-law up the mountain with a mercury barometer to measure elevation.

Some of the more frequently encountered pressure units are listed in Table 1. In this text we shall use the unit $(\mathrm{Pa})$ and we sha 11 frequently indicate in brackets the same pressure in more familiar units. These units will vary with the range, torr being preferred for vacuum measurements, psi for Tow and medium pressures, kbar for high pressures.
Table 1. Conversion Factors

to Pascals for various pressure units

To convert from

multiply by*

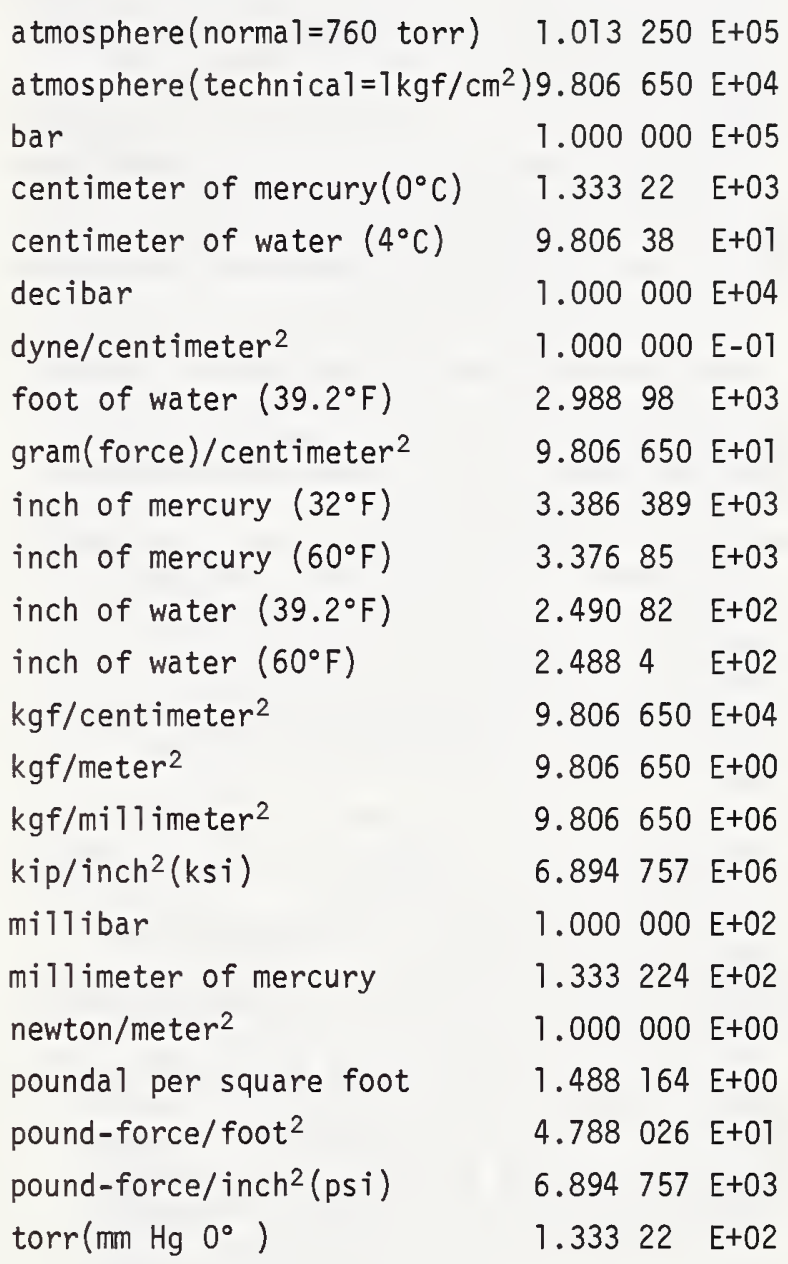

*The notation $E+n$ means multiplication by 10n 
Pressure Scale:

In any branch of metrology, the establishment and universal acceptance of a primary scale upon which all interpolation and extrapolation functions and devices can be based and to which they can be referred is of fundamental importance. In general, the establishment of such a scale will involve specific procedures, apparatus, and precautions associated with the measurement in question and will be as closely related to the fundamental definition of the measured quantity as apparatus will permit.

The techniques and apparatus associated with the primary scale should be as simple as possible and the process should be a direct measurement of the quantity itself. It is preferable not to involve averaging, differentiation, integration, or other mathematical manipulations implied by a theoretical treatment. It is not expected that specific procedures and details will be permanent but, rather, that they will be temporarily accepted by the scientific community until a more direct and reliable or more accurate technique can be demonstrated. The fundamental nature, the reliability, and the accuracy will be of prime importance in contrast to sensitivity, convenience, and availability. It would be desirable to have but one technique or apparatus extend over all ranges of the measured quantity, but such a condition is generally not possible.

Based on criteria of this type, two basic measuring systems with a variety of modifications have been proposed and used rather widely as a basis of a primary pressure scale: (a) the mercury manometer (including multiple and differential manometers), and (b) the free-piston or deadweight pressure gage (also called a piston manometer, pressure balance, or unpackedpiston gage). In a practical sense the use of the mercury manometer, has been limited to pressures bet:reen $0.1 \mathrm{~Pa}$ and $200 \mathrm{kPa}$. One very elaborate system built by Bett, Hayes, and Newitt (1954) was designed for use to $230 \mathrm{MPa}$ al though no measurements above $70 \mathrm{MPa}$ have been reported by these researchers. The free-piston gage is in common use to over $1 \mathrm{GPa}$ (10 kbar) and has been successfully used to $2.6 \mathrm{GPa}$ by Johnson and Heydemann (1967) and to $2.5 \mathrm{GPa}$ by Konyaev (1961) but with serious difficulty.

Since pressure comparisons require uniformity of pressure throughout the system or combination of systems, a primary pressure scale must be based on a truly hydrostatic system. Both of the systems proposed above are so based. At higher pressure (above 5 $\mathrm{GPa})$, this requirement of hydrostaticity represents a rather severe ultimate limitation on a primary pressure scale as discussed herein. Other scales applicable to higher pressures have been proposed as discussed in other sections of this report, but they cannot be considered to fit the above criteria of a primary scale and cannot be currently considered as such.

At pressures above $2.5 \mathrm{GPa}$, several apparatus of the piston-cylinder type have been built and pressure values have been reported. In these systems, various techniques have been used to approximate the conditions of the free-piston gage, but to date such approximations have diverged rather drastically from the criteria outlined above. It appears obvious that the best current approximations to a primary scale above 2.5 GPa are the piston-cylinder systems. However, significant improvement must be made in this technique before its reliability will be greater than indirect extrapolation techniques directly tied to the primary scale at lower pressures.

In the U.S. the pressure scale is primarily based on direct pressure measurements with controlled clearance piston gages as described in the next section and, to some extent, mercury filled manometers. Great Britain, Canada and the USSR base their pressure scales also upon piston gages but employ theories and evaluation methods different from those used in the U.S.; Germany and Italy are presently setting up standards of pressure using the controlled clearance piston gage principle.

A large variety of transfer standards and interpolation gages are in use. Two prob1 ems are obvious: There are no practical fixed points on the pressure scale below about $700 \mathrm{MPa}$ and none of the many types of interpolation gages is as adequately characterized as the platinum resistance thermometer serving as the interpolation gage for a large region of the temperature scale. Both of these facts have led to the initiation of research and development work aimed at improving this situation. 


\subsection{Basic Technical Infrastructure}

\subsubsection{Documentary Specification System}

\subsubsection{Standardization Institutions}

It is not surprising that the very widespread use of pressure had led to a proliferation of organizations writing often conflicting standards for pressure gages, transducers and measurement procedures.

There is no formal international agreement on a pressure scale nor is there any one organization clearly to succeed.

International organizations with a stake

in pressure standards are

Bureau International des Poids et Mesures (BIPM),

Organization Internationale de

Métrologie Legale (OIML),

International Union for Pure

and Applied Chemistry (IUPAC),

International Union for Pure and

Applied Physics (IUPAP),

International Association of High

Pressure Researchers (AIRAPT).

Of these organizations only IUPAC has made a serious attempt to prepare an international pressure scale. OIML has written two manufacturing standards for pressure gages.

Legal and regulatory standardizing organizations within the U.S. are

Federal Aviation Administration (FAA), Energy Resources Development

Administration (ERDA).

Voluntary standards for pressure measurements and gages are written by a large number of organizations. The more important ones are:

American Society of Mechanical

Engineers (several committees) (ASME)

American Society for Testing and

Materials (ASTM)

Society of Automotive Engineers (SAE),

Factory Mutual System (FME)

Compressed Gas Association (CGA),

Instrument Society of America (ISA),

Scientific Apparatus Makers Association (SAMA)

American National Standards

Institute (ANSI),

American Vacuum Society (AVS),

Air Transport Association (ATA),

American Welding Society (AVS).
The military specifications written by the Department of Defense for the purpose of procurement have had great influence on practices in the dissemination of pressure measurements, quality control and design.

These "Milspecs" occupy a place intermediate between the voluntary and legal standards.

ANSI through its associated engineering societies has probably the most significant influence on the system. Working on voluntary standards for pressure measurements are the B40 Committee for Pressure Gages, the High Pressure Research Committee, the High Pressure Technology Committee of the Pressure Vessel and Piping Division, the Power Test Code Committee (a11 ASME), an ISA Committee on Manometry, committees of the Compressed Gas Association, the American Can Manufacturers, the SAE, the ATA and many others. Traditionally these committees were concerned with writing standards, often dictated by safety considerations, for gages and components. The pattern is now beginning to change and more attention is being paid to the problems of disseminating accurate measurements, assessing errors and providing uniform measurements throughout the system. NBS is actively participating in this work.

\subsubsection{Survey of Documentary Standards}

The large number of standards that influence the field of pressure and vacuum measurements might be divided into three groups:

a.) Standards for measuring devices. These may either be performance standards or they may be construction standards. Most American standards are of the first kind, while several standards recently proposed by OIML are construction standards. This duality poses a problem for export of American-made devices.

b.) Standards for procedures. These standards describe the type of instrumentation and the methods to be used to achieve a certain calibration, as for example, of an altimeter. Also in this category are standards or recommendations on numerical evaluation and error calculation. Not much attention has been paid to the latter but, through our urging, several such standards or recommendations are now being considered.

c.) Safety standards. A large group of important standards deals with safety aspects in various ways. These may be standards for pressure vessels, pressure switches, components etc. They often require pressure measurements and calibration only in the design or test phase. In other cases-as, for example, on nuclear reactors, aircraft, compressors or tanks- 
continuous measurements within certain close tolerances are required.

It would serve no purpose to list here a11 standards applicable to the national pressure measurement system. However, in order to illustrate the variety of standards we are including a table of standards that must be observed in airtransportation. (Table 2).

Table 2. Standards for Altitude and Pressure Measurements on Aircraft

Subject Organization Identification

\begin{tabular}{|c|c|c|c|}
\hline Altimeter, Airborne & RT & DO & 103 \\
\hline $\begin{array}{l}\text { A1timeter, Pressure } \\
\text { Actuated }\end{array}$ & SAE & 392 & CAS \\
\hline $\begin{array}{l}\text { A1timeter, Pressure } \\
\text { Compensated }\end{array}$ & SAE & 415 & AS \\
\hline $\begin{array}{l}\text { A1 timeter, Airborne } \\
\text { Radar }\end{array}$ & RT & DO & 123 \\
\hline $\begin{array}{l}\text { Altitude Digitizer } \\
\text { Equipment }\end{array}$ & SAE & 855 & AS \\
\hline $\begin{array}{l}\text { A1titude Commercial } \\
\text { Transport }\end{array}$ & SAE & 505 & AIR \\
\hline $\begin{array}{l}\text { Pressure Actuated } \\
\text { Rate of Climb Ind. }\end{array}$ & SAE & 429 & AS \\
\hline $\begin{array}{l}\text { Pressure Actuated } \\
\text { Rate of Climb Ind. }\end{array}$ & SAE & 394 & AAS \\
\hline $\begin{array}{l}\text { Crew 0xygen Mask } \\
\text { Assembly }\end{array}$ & SAE & 452 & AAS \\
\hline $\begin{array}{l}\text { Pressure Fueling } \\
\text { Simul. for Aircraft }\end{array}$ & SAE & 816 & ARP \\
\hline $\begin{array}{l}\text { Pressure Fueling } \\
\text { Systems }\end{array}$ & SAE & 775 & ARP \\
\hline $\begin{array}{l}\text { Pressure Instrum., } \\
\text { Fue } 1,0 i 1 \text { \& Hydraulic }\end{array}$ & SAE & 408 & BAS \\
\hline $\begin{array}{l}\text { Pressure Refueling } \\
\text { of Aircraft }\end{array}$ & SAE & 74 & AIR \\
\hline $\begin{array}{l}\text { Pressure Release De- } \\
\text { vices, Aircraft wheel }\end{array}$ & $\begin{array}{l}\text { SAE } \\
\text { Is }\end{array}$ & 707 & AS \\
\hline $\begin{array}{l}\text { Pressure Trans. for } \\
\text { Aerospace testing }\end{array}$ & ISA & S37. & \\
\hline $\begin{array}{l}\text { Pressure Trans. for } \\
\text { Aerospace testing }\end{array}$ & ISA & RP 3 & 37.3 \\
\hline $\begin{array}{l}\text { High Pressure Hose } \\
\text { Assem., Aircraft }\end{array}$ & SAE & 614 & AARP \\
\hline $\begin{array}{l}\text { Airplane Cabin } \\
\text { Pressurization }\end{array}$ & SAE & 367 & CARP \\
\hline $\begin{array}{l}\text { Recommended Prac } \\
\text { for Manometer T }\end{array}$ & ISA & $\mathrm{RP}$ & \\
\hline
\end{tabular}

Table 2 (cont.)

Subject

Organization Identification

$\begin{aligned} & \text { Airborne Trans- } \\ & \text { ponder Equipment }\end{aligned}$
$\begin{aligned} & \text { Aircraft Hydraulic SAE } \\ & \text { \& Pneumatic Systems }\end{aligned}$
$\begin{aligned} & \text { Aircraft Hydraulic SAE } \\ & \text { \& Pneumatic Systems }\end{aligned}$
$\begin{aligned} & \text { Aircraft Hydraulic SAE } \\ & \text { \& Pneumatic Systems }\end{aligned}$
$\begin{aligned} & \text { Aircraft Hydraulic SAE } \\ & \text { \& Pneumatic Systems }\end{aligned}$
$\begin{aligned} & \text { Aircraft Engine } \\ & \text { Perform. Altitude SAE } \\ & \text { Graphs }\end{aligned}$
$\begin{aligned} & \text { Remote Serviced Air SAE } \\ & \text { Data Instruments }\end{aligned}$
$\begin{aligned} & \text { Maxim. Allowable } \\ & \text { Airspeed Instrum. SAE }\end{aligned}$
$\begin{aligned} & \text { Pitot or Pitot-Static } \\ & \text { Pressure Tubes }\end{aligned}$
$\begin{aligned} & \text { Mach Meters } \\ & \text { SAE }\end{aligned}$
SAE

Other important standards, issued by the ASME in the B40-series, deal with pressure gages of various types. The ASME pressure vessel code, although extending only to $20 \mathrm{MPa}$ (3000 psi), is of great importance for the design, testing and certification of thousands of pressure vessels and its extension to higher pressure is now before the appropriate committees as urgent business. Pressure measurements are also covered in the performance test code for power plants (PTC 19). A complete 1ist of applicable standards is found in "An Index of U.S. Voluntary Engineering Standards, NBS Special Publication 329," and its supplements.

\subsubsection{Instrumentation System}

\subsubsection{Measurement Tools and Techniques}

Physical Reference Standards:

The pressure scale from about $1 \mathrm{kPa}$ to $2.5 \mathrm{GPa}$ is based upon direct pressure measurements with piston gages of various designs. Up to about $5 \mathrm{MPa}$ (600 psi) gases and above $5 \mathrm{MPa}$ liquids are used as pressure transmitting media. At pressures exceeding $2.5 \mathrm{GPa}$ (25 kbar), piston and cylinder or piston and die assemblies are used to generate and measure pressure. A11 of these 
gages have two problems in common: the determination of the effective area and the determination of the change of this area with pressure. Of the various types of gages, only the controlled clearance piston gage lends itself to a direct and primary calibration. All other piston gages need to be calibrated by comparison. However, they constitute transfer standards with a precision and stability that are not matched by many other mechanical devices.

Pressure measurements below $200 \mathrm{kPa}$ (2atm) down to $10 \mathrm{mPa}\left(10^{-4}\right)$ torr are frequently based on measurements with manometers. These are considered primary standards as they can frequently be calibrated in terms of the basic units of length, mass and time. They are, in principle, capable of operating with lesser uncertainties than piston gages. Many types are commercially available but few of them are designed to minimize the largest single source of uncertainty: temperature. Mercury is commonly used as manometric fluid. Vacuum pump oils are used at very low pressures. The overlap of the operating ranges of manometers and piston gages from 1 to $200 \mathrm{kPa}$ provides a welcome chance for a comparison between basically different primary pressure standards.

In the vacuum range, that is below about $10^{2} \mathrm{~Pa}$ (1 torr), a variety of standards are used, which are based on volume expansion, pressure division (conductance devices) or pressure multiplication (compression manometers).

\section{Piston Gages:}

Figure 1 (a) recalls the principle of a simple piston gage. A piston of well known area $A_{p}$ is fitted into a cylinder. Pressure is supplied to the cylinder and the resulting force $\mathrm{pA}$ is counteracted by loading the piston with sufficient weight to balance this force. In practice, the effective area $A_{0}$ of the piston gage is not equal to the Area $A_{p}$ of the piston but is more nearly equal to the arithmetic mean of the area of the cylinder $A_{c y l}$ and that of the piston $A_{p}$

$$
A_{0}=\frac{1}{2}\left(A_{p}+A_{c y l}\right) \text { and } p=\frac{F}{A_{0}}
$$

Both $A_{p}$ and $A_{c y l}$ are not constants, but are functions of pressure, temperature, and load. It is possible that the effective area is also a function of the viscosity of the pressure transmitting medium; it may be a function of speed and direction of rotation and there may be other influences that we are not presently aware of. The largest single effect on $A_{0}$ is the dilation of the cylinder due to the internal pressure $p$. This is
(0)

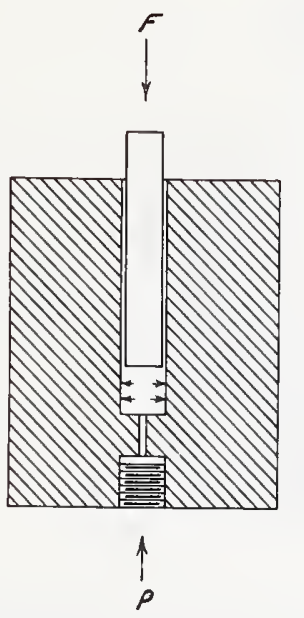

(b)
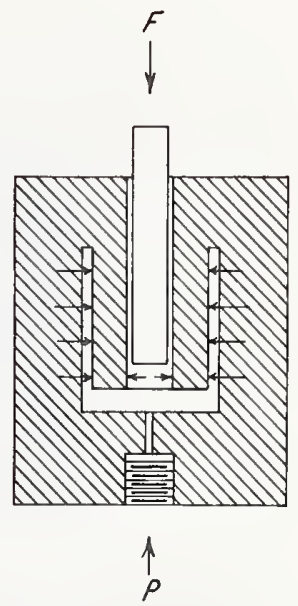

Figure 1. Piston gage, schematic

taken into consideration by multiplying $A_{0}$ with $(1+b p)$, where $b$ is called the pressure coefficient of the effective area. In order to reduce the dilation effect, which becomes so large at high pressures as to make gages inoperable beyond a certain pressure, the re-entrant cylinder shown in figure $i(b)$ was introduced. Here the pressure p actually tends to reduce the area of the cylinder at higher pressures.

In either case it is extremely difficult to predict the pressure coefficient on theoretical grounds, and before use of any such piston gage its effective area and pressure coefficient must be determined by a calibration.

To circumvent the difficulty posed by the pressure coefficient, the so-called controlled-clearance piston gage was introduced by Johnson and Newhall. The principle is shown in figure 2. Here the cylinder is surrounded by an annular space which is filled with $0 i 1$ and pressurized (jacket pressure $p_{j}$ ) by a separate pump. The dilating effect of the internal pressure can thus be compensated and the cylinder can be made to conform to the piston. Now the change in effective area is determined by the small change in area of the piston, which is amenable to mathematical analysis (Johnson), and by the clearance between piston and cylinder controlled by the jacket pressure Pj. 


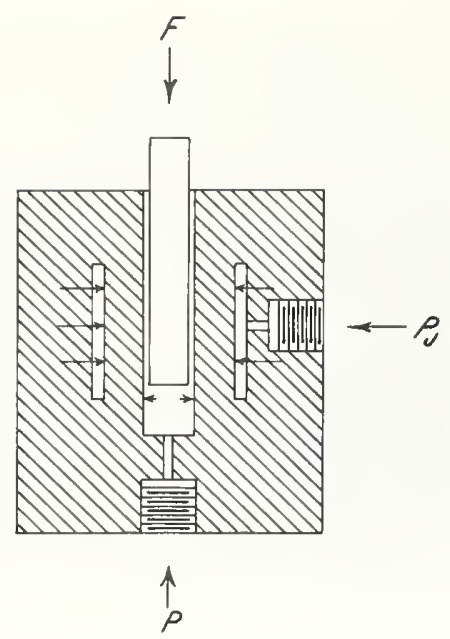

Figure 2. Controlled-clearance piston gage, schematic

The change of effective area of controlled clearance piston gages due to piston distortion is taken into consideration by multiplying $A_{0}$ with $(1+b p)$. The pressure coefficient b for controlled-clearance piston gages can be determined from the elastic constants of the piston material. Note that the pressure coefficient $b$ for controlled-clearance piston gages may be two or more orders of magnitude smaller than that for simple piston gages.

The effect of the jacket pressure on the effective area can be described by the term $1+d\left(p_{z}-p_{j}\right)$, where $p_{z}$ is the jacket pressure for which, at a particular internal pressure $p$, the clearance between piston and cylinder is reduced to zern. $p_{z}$ is therefore a function of pressure $p$ or load M. $d$ is the fractional change of area with jacket pressure.

With these terms and a few additional corrections the pressure generated by a controlled-clearance piston gage is described by

$$
p=\frac{M g\left(1-\rho_{a i r} / \rho_{M}\right)+\gamma C}{A_{0}\left[1+\left(\alpha_{C}+\alpha_{p}\right)\left(T-T_{r}\right)\right](1+(d+e m+}
$$

$$
\left.\left.\overline{f M^{2}}\right)\left(p_{z 0}+s_{z} M+q_{z} M^{2}-p_{j}\right)\right]
$$

where $\operatorname{Mg}\left(1-\rho_{\text {air }} / \rho_{M}\right)$ is the force exerted on the piston by the mass of weights $M$ with a correction for a ir buoyancy, $\gamma C$ is the force generated by the surface tension $\gamma$ of the pressure fluid through which the piston emerges. $C$ is the circumference of the piston at that point of emergence. [ $[+$ $\left.\left(\alpha_{C}+\alpha_{p}\right)\left(T-T_{r}\right)\right]$ corrects for changes of temperature; $\alpha_{c}$ and $\alpha_{p}$ are the thermal expansivities of the cylinder and piston respectively. $T_{r}$ is the temperature for which $A_{0}$ is known and $T$ is the temperature of the gage at the time of measurement. The other terms have been discussed above and are here expanded to quadratic functions of $M$ since our experience shows that the characteristics of piston gages often require quadratic functions for their description.

Controlled-clearance piston gages are commercially available both for pneumatic and hydraulic operation over a wide range of pressures. A controlled clearance piston gage capable of generating more than 2500 $\mathrm{MPa}(370,000 \mathrm{psi})$ is in operation at NBS.

\section{Manometers:}

Manometers measure pressure by balancing the pressureof a column of 1 iquid against the unknown pressure. The force per-unit-area generated by a liquid is

$$
\mathrm{p}=\mathrm{gh} \rho
$$

where $g$ is the local acceleration due to gravity, $h$ is the height of the column and $\rho$ is the density of the liquid. Numerous devices have been proposed to accurately locate the position of the meniscus of the liquid column and to transfer this position to a scale. The most precise manometers use capacitive detectors for the location of the menisus. Interferometric methods appear most promising for the future and an interferometer manometer is under construction at NBS. It uses beams of light from a carbon dioxide laser (10.6 $\mu \mathrm{m}$ wavelength) to locate the menisci and then measures their displacement in terms of the wavelength of the laser light. Fig. 3 shows a diagram of the principal components. The phase modulator permits the extraction of directional information from the output signal.

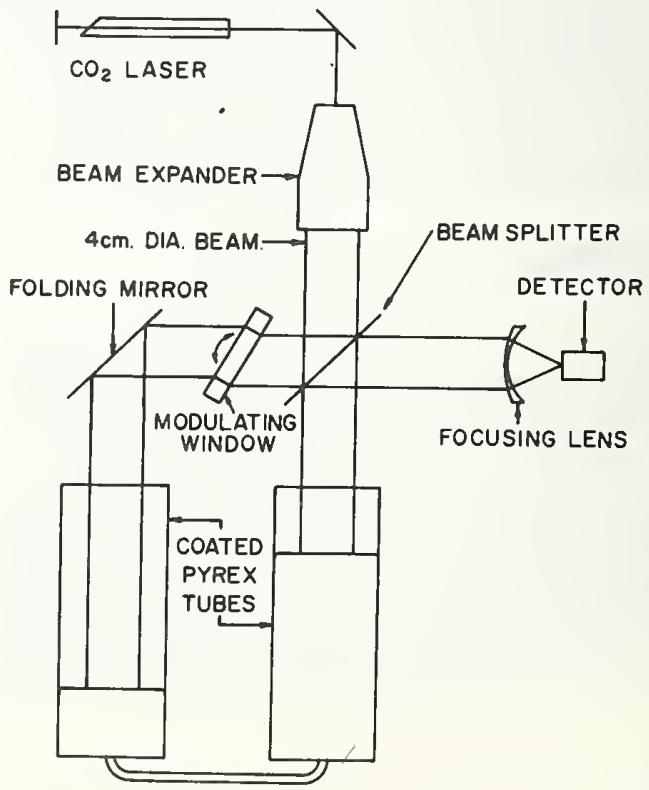

Figure 3. Infrared Lașer Interferometer Manometer, schematic 
There are a number of major sources of error. The most conspicuous one is the density $\rho$ of the manometric fluid and its temperature dependence. The density of mercury is known to about 1 or 2 parts per million at $20^{\circ} \mathrm{C}$ but it changes by more than 180 parts per million per degree Celsius. Although this is a well known fact, it is frequently not sufficiently taken into account in commercial manometer designs. Vertical adjustment of the scale is another source of error. Many difficulties arise from the low viscosity of mercury, which makes it difficult to locate its surfaces in the presence of vibration. Mercury surfaces are easily contaminated though oxidation of dissolved contaminants. Its high surface tension causes a depression of the meniscus that depends predictably on the size of the tube and depends unpredictably on the properties of the surface that the mercury is in contact with.

\section{Dissemination of Accurate Measurements:}

There are, in principle, two ways to transfer the accurate pressure measurement from NBS standards into the field: by sending a calibrated transfer standard into the field for in situ calibration of the customer's standard or by receiving the customer's standard for calibration at NBS. With few exceptions the latter way is presently favored. One of the primary reasons is the cost of the transfer standard and the time required to perform a calibration, including shipping the transfer standard forth and back. NBS would require many transfer standards and a large amount of work to keep them in calibration. Conversely a customer sending his standard to NBS would lose the use of his standard only once every three years for a period of between 4 and 8 weeks. Until a transfer standard can be developed that is as stable and precise as a piston gage, but easier to use and ship, we expect to do most of the calibration work at NBS by comparing the customer's instruments with NBS standards in "cross-float" operations.

In a piston gage "cross-float", if properly executed, the pressure $p^{\dagger}$ generated by the test gage equals that generated by the standard gage $p^{S}$ at the reference level of the test gage. This pressure is referred to simply as pressure $p$.

$$
p=\frac{F^{T}}{\left(A_{0, O}^{\top}\left(1+b_{1, O P}^{\top}+b_{2, O}^{T} P^{2}\right)\right.}
$$

where

$$
F^{T}=\frac{M g\left(1-\frac{\rho a i r}{\rho M}\right)+\gamma C}{T+\left(\alpha_{p}+\alpha_{c}\right)\left(T-T_{r}\right)}
$$

is the force exerted on the test gage piston,

$$
\begin{array}{ll}
A_{0}^{T}, 0 & \begin{array}{l}
\text { is the effective area of the } \\
\text { test gage, }
\end{array} \\
b_{1}^{T}, 0 & \begin{array}{l}
\text { is the fractional change of } \\
\text { effective area of the test gage }
\end{array} \\
b_{2}^{T}, 0 \quad \begin{array}{l}
\text { with pressure, and } \\
\text { effective area of the test }
\end{array} \\
\text { gage with the square of the } \\
\text { pressure. }
\end{array}
$$

Note that for simplicity the temperature correction of the area has been lumped with the force $\mathrm{F}^{\top}$.

All data computations are performed by a digital computer where a comprehensive analysis of the cross-float is obtained. The available information is tabulated and plotted in various ways to test for errors in the compilation of input data and for deficiencies in the gages or the calibration procedure and to present the resuits of the piston gage cross-float. A comprehensive calibration report is supplied to the customer.

In principle, instruments other than piston gages can be calibrated at NBS and used as transfer standards. This would entail generating a number of well known pressures with one of the primary standards and recording the output of the transducer connected to the standard. The results can be evaluated by fitting polynomials of various degrees in either pressure or output reading to the experimental data. This has been done in the past, but the lack of adequately characterized transducers presently precludes the wide use of this method. However, we are presentiy preparing a program, which will lead to the production of reliable data on transducers with the expectation that one or two transducers will emerge which can be used with confidence as transfer standards. This program is described elsewhere in this report. One must note that, in the important area of flight control instrument calibration, large numbers of transducers are used in spite of the absence of generally available data on long-term stability etc. 
Very similar principles are followed when calibrations are performed against the primary standard manometer. In any calibration the customer receives a detailed report of the test with all pertinent data, with a statistical analysis and with clear statements of the estimated uncertainty. The customer, often an instrument manufacturer, is only the first link in the long calibration chain down to the end point of use.

\section{The Calibration Chain}

Fig. 4 illustrates an example of a calibration chain. In the NMS for pressure there exist hundreds of such chains, which are often connected with each other and usually have an interface with NBS somewhere near the top. The calibration chain illustrated here begins with one of the primary standards at NBS; in this case the $150 \mathrm{MPa}$ controlled clearance piston gage. This gage has uncertainty of about $35 \mathrm{ppm}$. A gage manufacturer's plant standard was compared to the primary standard at a number of pressures using the cross-float methods discussed in the section on Dissemination. A total of 26 comparisons were made. The evaluation renders a set of constants for the gage manufacturer's plant standard with uncertainties determined by those of the primary standard and by the comparison. The gage manufacturer's Plant Standard is in turn used to calibrate instruments sold to customers. The customer elevates the gage

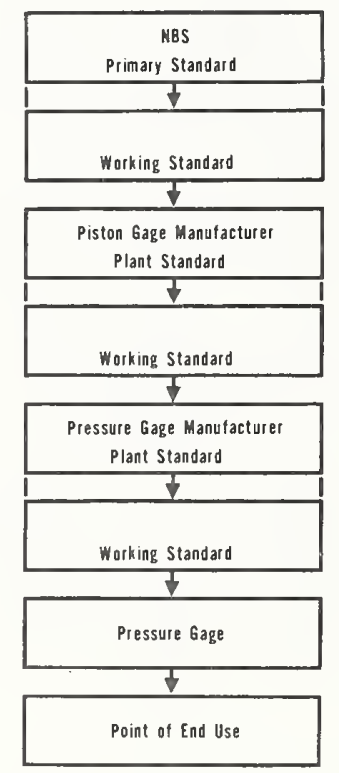

Example of a Calibration Chain

Figure 4. Calibration Chain purchased from the gage manufacturer to the level of plant standard and uses it to calibrate working standards. These working standards are then transferred to the various divisions and departments where they may be used to calibrate pressure gages and transducers used in a production process. We are now six transfers away from the top of the calibration chain. This calibration chain is typical. It is by no means a particularly long one; many examples can be found where there are more than six links in the calibration chain.

Not all calibration chains start at NBS. There are a number of laboratories with primary pressure standards. In a few cases these are controlled-clearance piston gages. Mostly, however, they are mercurial manometers. Both of these instruments are capable of being calibrated in the field. Some chains beginning with primary standards not at NBS nevertheless have links at lower levels with chains connected with NBS, affording them a certain degree of measurement assurance.

The instruments used in the transfer of measurements are almost exclusively piston gages, at least in the upper part of the chains. Piston gages of very high quality are capable of a precision and repeatability that occasionally approach one part per million but usually range from 3 to $12 \mathrm{ppm}$. Even if allowance is made for uncertainties introduced by various sources of error during a transfer, it is possible to propagate pressure measurements with errors of less than 20 ppm per link under carefully controlled conditions, with well trained personnel and high quality instrumentation. In many situations these conditions cannot be met. Well trained personnel and/or controlled environments may not be available. Cost is often an important limitation. Speed may be a consideration. Consequently one finds that near the lower end of a calibration chain transducers replace piston gages and instead of adding $20 \mathrm{ppm}$ per link the uncertainty is increased by a factor between three and ten. This tends to drop the accuracy of pressure measurements very rapidly and thwarts even the boldest attempts near the top of the chain to improve the situation.

Until now we have been looking down the calibration chain; let us now change our point of view and look up the chain from the point of use. Take tire inflation pressures as the measurement to be performed as illustrated in table 3 . This is an example of a chain that is uncomfortably long even for such a crude measurement. An uncertainty of no more than 1 psi should be allowed for the inflation pressure. The figure 
Table 3. Tire gage calibration

\begin{tabular}{|c|c|c|c|}
\hline OPERATOR & nBJECT/INSTRUMENT & RFEUIRED ACC. & Acc, LOST IN TransFER \\
\hline YOU AND I & TIRE & I PSI & FACTOR 3 \\
\hline YOU AND I & TIRE GAGE & 0.3 PSI & FACTOR 3 \\
\hline TiRe Gage MANU, & RENCH STD. (BOURDON) & $\eta .1$ PSI & FACTOR 3 \\
\hline TiRe fage Manu, & "ORKING STD, (ROURION) & $0, \cap 3$ PSI & FACTOR 3 \\
\hline TIRE GAGE MANU, & Plant Std. (Piston fiage) & $7.01 \mathrm{PSI}$ & 3ी PPM \\
\hline PRESS, faGe "'ANU, & "ORKIng StD, (Piston fage) & $\eta, M 7 \mathrm{PSI}$ & 20 PPM \\
\hline PRESS, fAGE "ANU, & Plant Std, (Piston fage) & ?.M5 PSI & $2 \cap$ PPM \\
\hline :BS & PRIMARY STD, (CCPG) & $0 . M B$ PSI & \\
\hline
\end{tabular}

shows clearly the accuracies required at various levels and the increments in uncertainty at each link of the chain.

An area with particularly critical needs for pressure measurements, as we shall demonstrate later, is air transportation. Because of the demand for accurate measurements and because NBS had for years neglected this area, most airlines and aircraft manufacturers have set up mercury manometers to serve as in-house primary standards. From these they disseminate accurate measurements through a variety of transducers to the point of use, namely the altimeter. The manometers are calibrated in terms of the basic units of length, mass and time as maintained by NBS and they are, in some cases, compared with NBS pressure standards by means of piston gages. In a measurement of such importance an additional assurance of the accuracy of measurement could be derived from a comparison between a calibrated altimeter and a transfer standard calibrated at NBS. Such measurement assurance program applied to standards near the end points of use could el iminate the need for many long calibration chains and at the same time reduce the uncertainty and the cost of the operation. But its main feature is the assurance at the point of use that a measurement of sufficient accuracy can indeed be rendered and that it is in agreement with the rest of the national measurement system.

\subsubsection{The Instrumentation Industry}

The instrumentation industry plays an important role in the national measurement system, since the majority of pressure measurements are disseminated through the instrument makers' standards laboratories. There are two layers of instrument makers: the producers of piston gages and the makers of transducers and indicating gages. The former receive calibrations from NBS and each of them transfers these to about forty customers per range. The transducer and gage manufacturers among these customers in turn transfer the measurements to their customers many of whom are not end users yet. The multiplication factor of these two layers is extremely large and, at least in quantity, the direct NBS to end user transappears to be insignificant.

Commensurate with the importance of the makers of standards there is close and growing contact between this industry and NBS, and recent activities at NBS have also started a growing cooperation between the transducer and gage manufacturers. There are approximately 150 manufacturers of gages and transducers with annual sales ranging from less than $\$ 100,000$ to several tens of millions of dollars.

With one exception, the piston gage manufacturers produce devices that are classed as transfer or secondary standards. One manufacturer makes primary standard piston gages. Two manufacturers offer vacuumbacked piston gages intended primarily for use in altimeter calibrations. Throughout this part of the instrumentation industry the price per instrument varies from a few hundred to several ten thousand dollars 
as the sophistication of the instruments increases. With the exception of the maker of primary standards (controlled clearance piston gages) all manufacturers maintain standards calibrated by NBS. Many of the primary standards are also sent to NBS for calibration.

The transducer and gage manufacturers traditionally have not been direct NBS customers. This is beginning to change as transducers and gages with greater precision become available. Several manufacturers have recently begun to obtain calibrations for their plant standards directly from NBS. In the future this cooperation will become much closer as NBS is beginning a transducer evaluation program. A similar program for gages may be instituted later. The variety of transducers and gages is even wider than that for piston gages. Among the gages the conventional Bourdon tube predominates with accuracies ranging from $5 \%$ down to $0.1 \%$. Three manufacturers produce quartz Bourdon tubes. At least two manufacturers produce force balanced Bourdon tube gages with significantly reduced hysteresis. Among the transducers strain gage types appear to dominate. Others use LVDT, reluctance or capacitive systems to sense the deflection of an elastic element. A new class of transducers with rather high resolution uses oscillating components, the resonance frequency of which is changed by the application of strain or stress. The prices for gages range from a few dollars to about one thousand dollars, those for transducers with or without read-out from below $\$ 100$ to about $\$ 10,000$.

In our opinion the lack of information on the performance of transducers and gages over longer periods of time is the chief obstacle to their extended use as transfer standards in the calibration chain. Much information about certain types has been accumulated by users, but the information is proprietary and not publicly available. We have found that manufacturers frequently misstate performance characteristics. Both overstatements and understatements are found. Inequities in the market place arise from the fact that users often write purchase specifications for transducers, which they cannot verify. As a result of NBS actions this situation is expected to change (see 4.2.1f).

Another group of instrument manufacturers produces manometers. These range in price from a few tens of dollars to about $\$ 50,000$ for the most elaborate instruments. Mercury, $0 i 1$ and water are frequently used as filling fluids. The market for the most sophisticated instruments used in altimeter calibration is dominated by two companies. Altogether ther $\epsilon$ are about 25 manufacturers in this field.
Since manometers are primary

standards, calibratable in situ in terms of the basic units of mass, length and time, NBS does generally not provide calibrated pressure standards for these manufacturers. However, the calibrations of the more accurate ones in the field are frequently compared with NBS primary standards through suitable transfer standards.

The situation in the vacuum gage industry is confused at best. Since there are no U.S. national standards, there are now very few direct connections between NBS and the industry. Large numbers of ionization gages, capacitance manometers, thermocouple gages etc. are produced with no chance to compare their calibration with a national standard. The absence of dependable primary standards in a central laboratory also precludes any measurements on the reproducibility, resolution and long term stability of these gages. Other countries as for example Japan, Great Britain and the Federal Republic of Germany, are in the position of having excellent standards laboratories serving their own, relatively small vacuum industries. This could easily convert the present U.S. positive trade balance for vacuum equipment into a negative one.

\subsubsection{Reference Data}

Although the use of reference data in the national measurement system for pressure is not extensive, there are several sets of data which are directly or indirectly of great importance. Among these are densities of manometric fluids, the standard atmosphere, the steam tables, fixed points on the pressure scale and the equation of state of sodium chloride.

\section{Density of Manometric Fluids}

Mercury is the fluid with the highest and best known density. It has traditionally been the choice manometric fluid although it has many properties that adversely affect its use and that are not well understood. The more prominent ones are its low viscosity, the rapid deterioration of its exposed surfaces, its high surface tension, and the variability of its contact angle with containment materials. The most precise determination of the density is that of A.H. Cook and N.W.B. Stone published in Phil. Trans. Royal Soc. London, Ser. A. 250, 279 (1957). The best determination of the thermal expansivity of mercury is that of J.A. Beattie et al. published in Proc. Am. Acad. Sci. 74. 371 (1941). The density and thermal expansivity 
of a siloxane manometer fluid (DC 704) were

determined by R.H. Orcutt and published in $\mathrm{J}$.

Vac. Sci. Technol. 10. \#4, 506 (1973).

Selected data are given in Table 4.

Table 4. Density of Manometric Fluids

\begin{tabular}{|c|c|c|c|}
\hline Substance & $\frac{\text { Temp. }}{\left({ }^{\circ} \mathrm{C}\right)}$ & $\frac{\text { Density }}{\left(\mathrm{g} / \mathrm{cm}^{3}\right)}$ & $\frac{\text { Therma } 1 \text { Exp. }}{\left(x^{\left.10^{-4}{ }^{\circ} C^{-1}\right)}\right.}$ \\
\hline $\begin{array}{l}\text { Mercury } \\
\text { Mercury } \\
\text { Water } \\
\text { Water } \\
\text { Water } \\
\text { DC } 704\end{array}$ & $\begin{array}{r}0^{\circ} \mathrm{C} \\
20^{\circ} \mathrm{C} \\
0^{\circ} \mathrm{C} \\
3.98^{\circ} \mathrm{C} \\
20^{\circ} \mathrm{C} \\
23^{\circ} \mathrm{C}\end{array}$ & $\begin{array}{c}13.59504 \\
13.54584 \\
0.999840 \\
0.999972 \\
0.998206 \\
1.0731\end{array}$ & 1.8159 \\
\hline
\end{tabular}

\section{Standard Atmosphere}

The Standard Atmosphere consists of a set of tables of atmospheric properties vs. geopotential and geometric altitude. It covers the range from -5000 to $+300,000 \mathrm{~m}$ and forms the basis for all altimeter calibrations and related measurements. It was prepared under the sponsorship of the Geophysics Research Directorate and the U.S. Weather Bureau. NBS maintains a computer code for the computation of altitude vs pressure tables in finer increments than those given in the published document.

\section{Steam Tables}

The Steam Tables are an internationallyagreed-upon tabulation of the thermodynamic properties of steam as a function of pressure and temperature. A large effort is expended in their improvement. Their area of application is mainly the power industry for the purpose of designing and operating steam turbines and engines. The tables are distributed in this country by the ASME.

\section{Fixed Points on the Pressure Scale}

For the calibration of high pressure apparatus in situ fixed points marked by phase transitions have been determined by a large number of researchers in the field. These points cover the range from about 500 $\mathrm{MPa}$ ( $5 \mathrm{kbar}$ ) to over $20 \mathrm{GPa}$ (200 kbar). An international conference held at NBS agreed on a set of fixed points to be used for high pressure calibrations and assigned best values to them. These have been published by E.C. Lloyd, C.H. Beckett and F.R. Boyd in Science 164, 860 (1969) and are in widespread use. Table 5 . 
Table 5. Fixed points on the pressure scale

\section{Transition}

Mercury Freezing Point at $0^{\circ} \mathrm{C}$

Bismuth I to II transition at $25^{\circ} \mathrm{C}$

Thallium I to II transition at $25^{\circ} \mathrm{C}$

Barium I to II transition at $25^{\circ} \mathrm{C}$

Bismuth III to $V$ transition at $25^{\circ} \mathrm{C}$
Pressure

$756.9 \mathrm{MPa}$

$2.555 \mathrm{GPa}$

$3.67 \mathrm{GPa}$

$5.5 \mathrm{GPa}$

$7.7 \mathrm{GPa}$
Uncertainty

$0.2 \mathrm{MPa}$

$0.006 \mathrm{GPa}$

$0.03 \mathrm{GPa}$

$0.2 \mathrm{GPa}$

$0.3 \mathrm{GPa}$
Two of the published points were determined at NBS. The mercury melting line is also used to provide reproducible pressure points for in situ calibrations. The publication in Science by Lloyd et al contains an equation for the pressure and temperature relation along the melting line. NBS is currently involved in generating improved data for this phase line particularly at pressures below $0.7 \mathrm{GPa}$.

\section{Equation of State of Sodium Chloride}

The equation of state of sodium chloride is used extensively for pressure measurements at very high pressures (above $2.5 \mathrm{GPa}$ ). It was determined by three or four groups and the results of these'groups agree within the estimated uncertainties of the measurement. Sodium chloride is mixed in with the charge or the material under test and $i$ ts density is determined from $x$-ray lattice measurements. The pressure can then be calculated from the known equation of state.

Other materials proposed for the same purpose are copper and aluminum.

\subsubsection{Reference Materials}

It appears highly desirable to provide reference materials for the substances discussed under 2.2.3 Reference Data. This is particularly true for manometric fluids like mercury and siloxane, where the lot to lot variation may exceed the inaccuracy of the density determination. The creation of such standards is now under discussion.

\subsubsection{Science and People}

The measurement of pressure is rarely an end in itself and it is therefore generally left to the national laboratories to improve existing primary standards and to develop new ones. The instrumentation industry is naturally interested in developing new, saleable products. The scientific and research oriented organizations are primarily users in this system. One must not overlook, however, the large amount of basic research underlying a 11 present primary and transfer standard developments. The manometer and the piston gage are both the fruit of basic research in thermodynamics. Strong impulses for improvements in the basic standards still come from areas of scientific research such as equation of state, thermodynamics, statistical physics, meteorology, oceanography and others. Strong contributions are made particularly for measurements at very high pressures by researchers in statistical and solid state physics.

Professional societies appear to have only a limited effect on the system. With the exception of the American Vacuum Society there is no professional society dedicated directly and exclusively to the measurement system for pressure, al though important contributions are made by several committees of the American Society of Mechanical Engineers, the Instrument Society of America and others. Most of these contributions are in the form of standards, procedures or recommendations. Another important, though indirect, contribution is the organization of professional meetings strengthening the dissemination of information which is otherwise scattered throughout the engineering literature. NBS contributes by organizing meetings, publishing papers, technical notes and monographs. Many of these NBS publications are the only available written material on the subject.

The lack of publications devoted to the subject of pressure measurement is symptomatic of the lack of formal education and training in this field. Most, if not all, persons now working in this part of the measurement system have no formal training in the measurement of pressure. Only one member of the NBS Pressure and Vacuum Section had prior experience with pressure standards. Engineers and technicians working in industrial pressure standards 
laboratories typically acquire all their specific, job-oriented skills on the job. Two manufacturers of pressure standards have formal courses for industrial personnel naturally inclined towards use of their own instrumentation. The American Vacuum Society arranges short courses in vacuum measurements, a comendable practice worth being copied by other societies. NBS has recently instituted training courses for pressure measurements in standards laboratories, which appear to be quite well accepted.

\subsection{Realized Measurement Capabilities}

\subsubsection{Pressure Ranges}

The range of industrial applications covers about 17 decades of pressure and vacuum from $10^{-7} \mathrm{~Pa}\left(10^{-9}\right.$ torr $)$ to $10^{10} \mathrm{~Pa}$ (100 kbar). Scientific applications exceed this range by several orders of magnitude in either direction. Of this total range NBS presently covers about one third, namely the range from $2 \times 10^{3} \mathrm{~Pa}(0.2 \mathrm{psi})$ to $4 \times 10^{8} \mathrm{~Pa}(60,000 \mathrm{psi})$ (see fiq. 5).

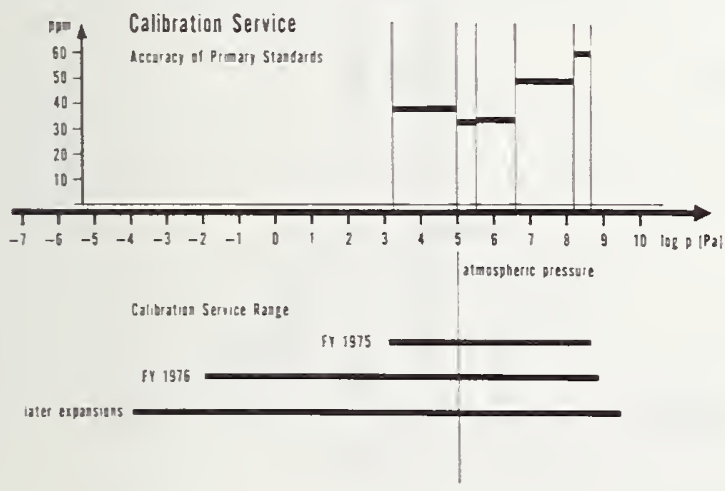

Figure 5. NBS Calibration

An extension down to $10^{-2} \mathrm{~Pa}\left(10^{-4}\right.$ torr $)$ and up to $7 \times 10^{8} \mathrm{~Pa}(100,000 \mathrm{psi})$ is anticipated for FY 76. NBS will then cover about $60 \%$ of the industrially used range. There will be no service to the research community working at pressures above about $7 \times 10^{8} \mathrm{~Pa}$ ( $7 \mathrm{kbar}$ ) and there will be no calibrations for the medium and high vacuum ranges unless a management decision is made to begin a vacuum calibration effort at NBS.

\subsubsection{Accuracy and Precision}

NBS pressure standards have systematic uncertainties ranging from 33 to $60 \mathrm{ppm}$ for standards used in the calibration service and up to $1000 \mathrm{ppm}$ for primary standards not in the calibration service(Table 6).

Table 6 . Uncertainty of primary pressure standards at NBS.

$\frac{\text { Range }}{[\mathrm{Pa}]}$
$2 \times 10^{3}(0.3 \mathrm{psi})$
to
$10^{5}(15 \mathrm{psi})$
to
$3 \times 10^{5}(50 \mathrm{psi})$
to
$4 \times 10^{6}(600 \mathrm{psi})$
to
$1.4 \times 10^{8}(20,000 \mathrm{ps} i)$
to
$4 \times 10^{8}(60,000 \mathrm{ps} i)$
to
$2.5 \times 10^{9}(25 \mathrm{kbar})$
to

$\frac{\text { Uncertainty }}{\text { [ppm] }}$

60

235 this range is not in calibration service

1000 this range is not in calibration service

The precision of these standards ranges from about $3 \mathrm{ppm}$ to about $15 \mathrm{ppm}$ within the calibration service range.

At the other end of the calibration chain are the required accuracies at the end point of use. These are generally difficult to assess in detai1. A large group of measurements with fairly well defined tolerances serves altimeter and airspeed indicator calibrations: measurement assurance for plant standards requires an accuracy of 20 ppm of the reading. Similar requirements hold for altimeter setting indicators (ASI). Maintenance of military equipment calls for accuracies of the order of $100 \mathrm{ppm}$ at pressures up to $7 \times 10^{7} \mathrm{~Pa}(10,000 \mathrm{psi})$. 011 well pressure gages are specified with a resolution of $1 \mathrm{ppm}$ and a comparable precision is required of the standard at pressures up to $10^{8} \mathrm{~Pa}(12,000 \mathrm{psi})$. Gage manufacturers need standards up to $7 \times 10^{8} \mathrm{~Pa}(100,000 \mathrm{psi})$ with an accuracy of $300 \mathrm{ppm}$. Transducer manufacturers, however, require accuracies of $20 \mathrm{ppm}$ or better for the evaluation and 
calibration of their products over a wide range of pressures. At pressures up to $10^{9}$ $\mathrm{Pa}(10 \mathrm{kbar})$ or higher, uncertainties of less than 100 ppm are now required for many scientific purposes, while 1000 ppm appears adequate for industrial purposes. For the range below $10^{2} \mathrm{~Pa}$ (1 torr), information on required accuracy was obtained from the Delphi study. (Data in table 7 for different applications). There are several areas of great economic significance, which now require measurements to better than $0.1 \%$ and tighter tolerances in the future. None of the requirements can be met by NBS.

Table 7. Required accuracy for vacuum measurements (all in percent)

Application $\quad \underline{\begin{array}{c}\text { Range } \\ \text { in torr) }\end{array}} 1$ to $10^{-3} \quad 10^{-3}$ to $10^{-6} \quad 10^{-6}$ to $10^{-9}$ below $10^{-9}$

Nuclear Reactor Safety

Systems

Chemical Plant, Refining etc.

Space Simulation Vehicle Satellite Test

Semicond. Manuf.

10

50

1

1

10

50

Metal Preparation

Electron Tubes,
0.1

0.1

0.1

0.1

0.1

1

1

0.1

0.1

0.1

10

0.1

0.7
Substrate $S_{j}, G_{e}$

0.1

Semicond. Manuf.

Vac. Deposition

Steel Specialties

CRT, Displays

Calibr. of Leak

Detectors

Calibr. of Std.

Leaks

Calibr. of Flight

Measurement of Pumping

Speed

Trans. Stds.
10

10

50

10

10

10

10

10

50

50

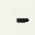

-

50

10

50

10

10


Many of the accuracy requirements 1 isted above that fall within the range where NBS presently offers calibration services can be met by available primary standards. In some cases, however, the dissemination poses a severe problem. There are three reasons: the first one is the often inadequate training of the personnel associated with these measurements, the second is our lack of knowledge on the performance of transfer standards, and the third is the length of the calibration chains. Actions taken to help improve the situation are described in chapter 4 of this report.

It is interesting to note that when one purchases a tire gage one has no assurance of its accuracy nor any means to have it checked. Neither the notoriously inaccurate air columns in gas stations nor the tire gages in the hands of gas station attendants are checked once they have left the manufacturers plant. Fig. 6 shows some results of tire gage calibrations done at NBS.

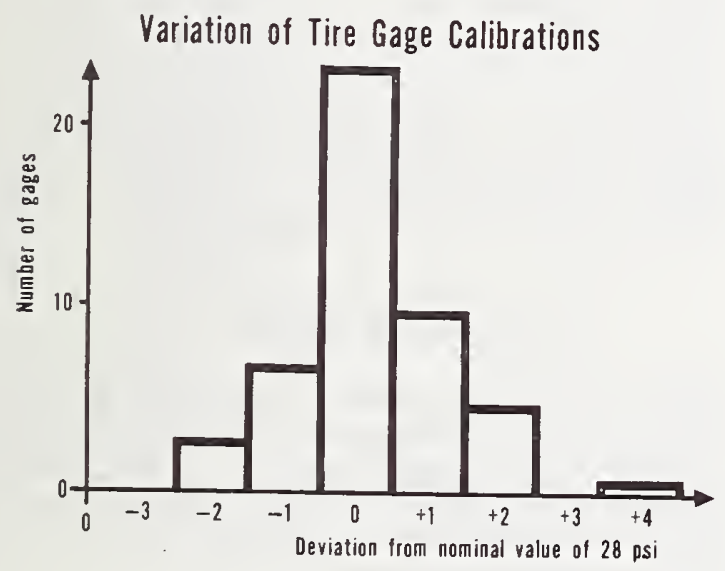

Figure 6. Variation of Tire Gage Calibration

Plotted is the number of gages reading a certain pressure for a constant set pressure. Such data were taken over a period of several months on tire gages owned by NBS staff. We will comment elsewhere in this report on the economic significance and desirability of this particular measurement (3.1.3).

\subsection{Dissemination and Enforcement Network}

\subsubsection{Central Standards Authorities}

Internationally only the organization for Legal Metrology (OIML) appears to affect the pressure measurement system. OIML has recently proposed a number of standards of pressure gages. These have not been ratified as yet by the U.S. delegation, nor is their ratification likely. Nevertheless these standards may form a trade barrier for U.S. exporters in those countries that have adopted these standards.

Within the United States the Department of Defense (DOD), through military specifications and standards, exerts great influence that is not restricted to its own suppliers. Energy Research and Development Administration (ERDA) and the Federal Aviation Administration (FAA) influence the system through specifications, recommendations and standards pertaining to their particular domain. The FAA lacks the measurement capability for rigorous enforcement of important standards.

\subsubsection{State and Local Offices of Weights and Measures.}

These offices are generally not equipped to provide pressure calibrations. They do, however, frequently calibrate weights for piston gages. Offices have been created in most states to certify the design of pressure vessels to be installed in the state. These generally follow the ASME Pressure Vessel Code.

\subsubsection{Standards and Testing Laboratories, and Services.}

A large number of commercial testing laboratories provide some 1 imited pressure calibration service (see table 8). In a few cases the standards have been calibrated at NBS and are maintained by personnel trained at NBS. In the majority of the cases these testing laboratories maintain a master gage with a calibration from the manufacturer for the testing and calibration of less accurate gages. An extensive listing of such testing laboratories is annually compiled by the National Conference of Standards Laboratories. Their use of the term "primary standard" in the listing may be misleading. These testing laboratories are an important part of the measurement system as an economical source for calibrations. For many users they are virtually the only avallable source.

Large industrial concerns frequently make their standards laboratories available to the public or at least to their subcontractors. Some NOD, ERDA and NASA laboratories do the same for their subcontractors. All of them perform a significant amount of calibration work for their own hierarchy. Standards are provided by NBS where possible. In the vacuum range, McLeod gages and dynamic expanders are most frequently used with no opportunity to provide uniform measurements throughout the system. 
Table 8. COMMERCIAL PRESSURE CALIBRATION LABORATORIES

P, "primary" standard in the terms of NCSL, denotes an accurate transfer standard as for example a piston gage or a good Bourdon gage

\section{Commercial Laboratories}

Al1 is Chalmers MFG

American Geophysical

Avco

Ba11 Brothers Research

Beckman Instruments

Bendix

Boeing

Burroughs

Collins Radio

Colorado Engineering Experiment

Dayton T. Brown

E. G. and G.

Electrical Testing Labs

E - Systems

Foxboro

Gage Lab

Gauge Repair Service

General Dynamics

General Electric

Harris Intertvpe

Hercules

Honeywe 11

Instruments East

Leeds \& Northrup

Clifton of Litton

Lockheed

Martin Marietta

McDonnel Douglas

$3 \mathrm{M}$

NAR, Rocketdyne

National Astro Labs

Raytheon

Rockwe11 International

Ruska Instruments

Singer

SSCO Standards Lab

Teledyne

TRW Sys tems

Varian

Volumetrics

Westinghouse Electric

\subsubsection{Regulatory Agencies}

The Nuclear Regulatory Commission (NRC) and Federal Aviation Administration (FAA) both influence important sectors of the measurement system. ERDA has excellent calibration laboratories in several of its plants that are capable of enforcing and verifying most or all specifications. The FAA lacks these capabilities at least for its enforcement network. Standards laboratories exist in the FAA Experimental Facilities. It is left to the airtransport industry to comply with the regulations and technical standards orders of the FAA (and the trade associations) and to provide their own standards and calibration hierarchy. FAA inspectors visit the certified laboratories and rework facilities to oversee the work, but they have no means to conduct a measurement assurance program. We at NBS feel that this puts a large and partially avoidable burden on the industry. Each of the airlines and aircraft manufacturers presently must maintain a primary standards laboratory. One central laboratory coupled to the users with a measurement assurance program could achieve the same end at a lesser total expense and provide for uniformity at the same time. The FAA has so far been unresponsive.

\subsection{Direct Measurements Transactions Matrix}

Table 9 contains schematic and summary information about transactions between users and suppliers of measurements, information and essential hardware. The community has been divided into 25 categories, which, with few exceptions are self-explanatory. These categories are

1 Knowledge Community: scientific organizations, professional societies technical publishing organizations, trade associations,

2 International Metrological Organizations,

3 Documentary Standards Organizations,

4 Instrumentation Industry.

5 NBS

6 0ther U.S. National Standards Authorities

7 State and Local Weights and Measures Offices.

8 Commercial Standards and Testing Laboratories. 
Table 9: Direct measurements transactions matrix

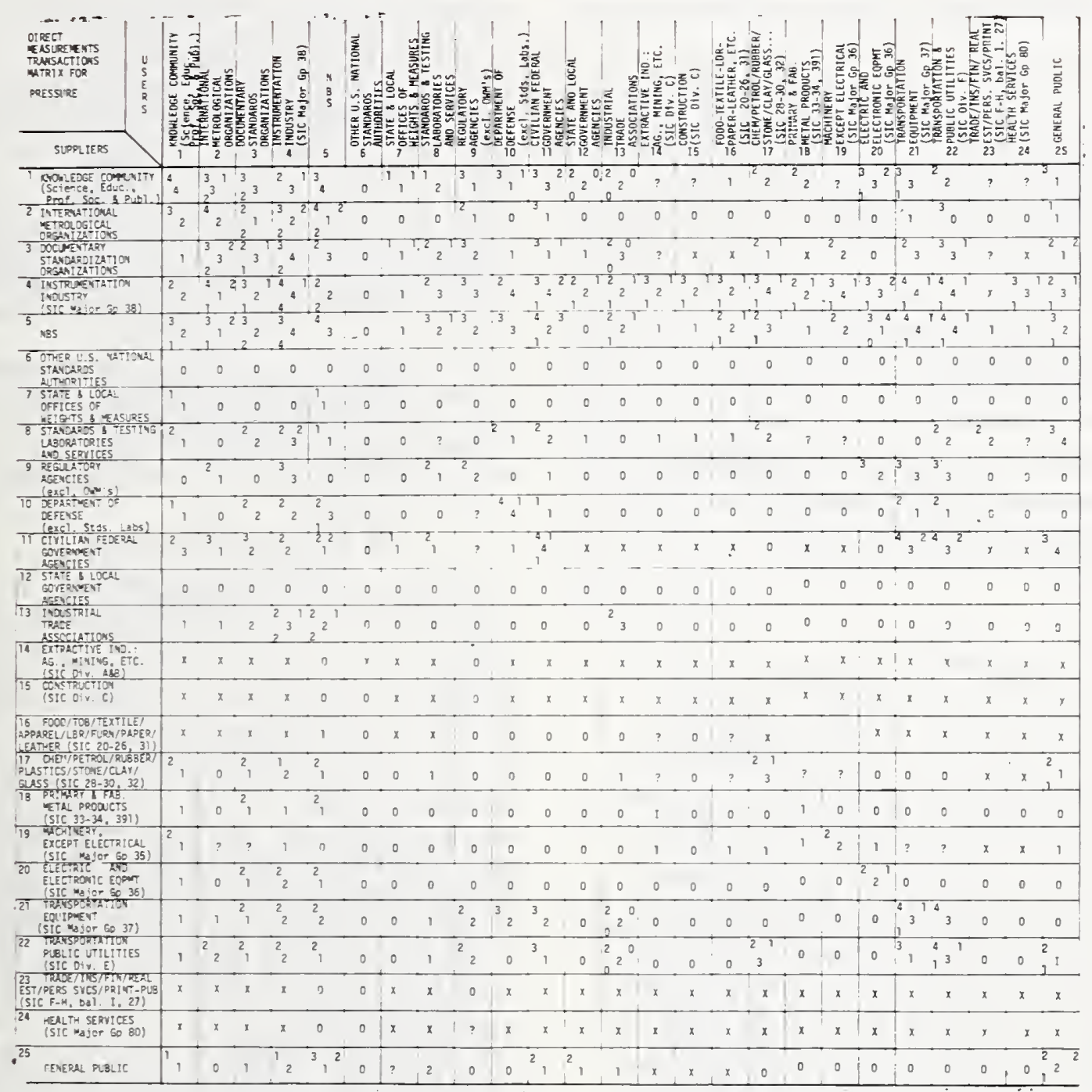

Key to matrix entries:
$[T]$ magnitude of transaction:
none
smal1
large
$[N]$ rate of change of transactions:
negative
stable
slowly growing
growing
fast growing
explosive [1] importance of transaction
for the recipient
not essential matter of convenience,
2 economically important; strongly desirable,
3 no satisfactory al ternate source; legally required,
4 very essential; sole source; matter of life and death.
[1] adeouacy of transaction
0 no foreseeable improvements needed or desirable
1 under control, but could be improved
2 marqinal, significantly inadeauate
3 seriously deficient
4 out of control, thoroughly unsatisfactory 
9 ReguTatory Agencies

10 Department of Defense (DOD)

11 Civilian Federal Government Agencies.

12 State and Local Government Agencies.

13 Industrial Trade Associations.

14 Extractive Industries.

15 Construction.

16 Food, Textile etc.

17 Chemical and $0 i 1$ Industry.

18 Metal Products.

19 Machinery except Electrical.

20 Electric and Electronic Equipment.

21 Transportation Equipment.

22 Transportation, Utilities.

23 Trade.

24 Health Services.

25 General Public.

Each category is entered twice, as supplier and as user. Up to five entries are made at each intersection. Their meaning is explained at the bottom of the matrix. These entries are not free from ambiguity: a transaction may be important for the user but not for the supplier or vice versa. Two large transactions in different parts of the matrix may have widely different economic consequences. There are 625 intersections with a total of more than 1000 entries. The discussion will therefore be limited to major features and major users.

The core of the measurement system is found in the $5 \times 5$ element submatrix in the upper left hand corner. A measure of the significance of this part is the mean of the "importance" entries in this submatrix of 2.7 compared to 0.5 for the rest of the matrix. Many of the transactions taking place here are information exchange. Only the dissemination of measurements from NBS to the manufacturers of standards, gages and transducers and between the three latter appear. There is ample indication of a large amount of feed-back in this part of the system. The second important part is the $5 \times 20$ element matrix in the upper right hand corner. This part shows the transaction from the core of the system to the users. The mean magnitude entry here is 1.4 (mean of the entire matrix 0.6) and mean importance entry is 1.4 (mean of the entire matrix $0.6)$. The predominant transactions are in the form of measurements. The $20 \times 5$ element matrix in the lower left hand corner gives the reverse interaction, namely, from the users to the core of the system. Naturally, these transactions are all in the form of information. In magnitude (0.8 vs. $0.6)$ and in importance (0.8 vs. 0.6$)$ they rank above the mean. The rest of the total matrix, a $20 \times 20$ element submatrix in the lower right corner, describes interactions in the lower echelons of the measurement system. Here the significant interactions are primarily within each category and they appear therefore along the diagonal.

NBS appears as a supplier of measurements to most of the users and at the same time it receives information from virtually all parts of the system. In several cases the information feedback is, however, insufficient.

\subsubsection{Highlights re Major Users}

The major users of measurements in the system are easily identified as those having entries 3 or 4 for magnitude. Among these are the manufacturers of standards, gages, transducers, the commercial testing laboratories, the industries in categories 17 to 22, and the government agencies. Exchanges go, for example, from NBS to Standards Manufacturers to NOAA to the Transport Industry, here primarily the airlines. Another chain goes from NBS to the Standards Manufacturers to the Equipment Manufacturers and thence in the form of essential auxiliary equipment to any of a variety of users. Most industries are important suppliers of their own services through extensive internal calibration hierarchies.

There are a number of motivations for using pressure measurements, some of which with their major constituents are:

$\begin{aligned} & \text { Safety: } \text { Aircraft Manufacturers } \\ & \text { Transportation } \\ & \text { DOD } \\ & \text { ERDA } \\ & \text { FAA } \\ & \text { General Public }\end{aligned}$

Calibration (product requires calibration to operate) Standards Manufacturers Gage Manufacturers Transducer Manufacturers Equipment Manufacturers 
Operational: (process pressures must be measured)

Aircraft Manufacturers

Transportation Industry

Chemical and $0 i 1$ Industry

Semiconductor Industry

NASA

NOAA

General Public

Performance: (accurately known pressures required for evaluation of performance)

Aircraft Manufacturers

Equipment Manufacturers

Gage Manufacturers

Transducer Manufacturers

Dissemination:

Standards Manufacturers
Commercial Testing
Laboratories
NOAA

Research: ERDA

NASA

Industrial $R+D$

Universities

It is now interesting to see whether these needs, for example those related to safety, are fully met. The FAA (Col. 9) is reponsible for tne safety of the nation's airlanes. Rapidly increasing traffic requires improved control of altitude, vertical and lateral separation, and air speed of planes in the major traffic lanes. New instrumentation must be used even though there may not be sufficient performance data available. In some cases the problem of calibrating the equipment being installed has not been solved. This, if not resolved, would constitute "inadequate transitions". An improvement is also needed in the aircraft manufacturing and transportation industries to tie all critical pressure measurements to national standards.

This improvement would Tikely be in the form of a measurement assurance system provided either by the FAA or the NBS, in the form of better characterized transfer standards, and in a few cases of more accurate measurements.

The services provided by NBS to the semiconductor industry are thoroughly unsatisfactory and, in fact, there just are no services. Measurements provided by the general public to the general public are found to be inadequate. This pertains to the fact that an automobile owner can not have his tire pressure measured reliably although the measurement of tire pressures is of significant economic impact(3.1.3).

\section{The End User:}

The end uses to which pressure and vacuum measurements are put are as varied as the types of gages, switches, transducers that are applied. Little can be gained from enumerating a 11 of them. It may be more revealing to have a somewhat closer look at an example for an end use that is more demanding than the tire gage calibration. The example deals with altimeter calibrations. We are using data obtained by the International Civil Aviation Organization and published in the "Manual for Barometry," DOC-Weather bureau.

Altimeters are used principally for the following purposes which require the measurement or control of the altitude of aircraft with respect to sea level or some other reference surface:

(1) Landing at an airport;

(2) Vertical separation between aircraft flying in different directions or at different speeds on an airway or elsewhere;

(3) Vertical clearance of terrain under instrument flying conditions;

(4) Miscellaneous aircraft operations that require knowledge of pressure altitude and other parameters; for example, the setting of engine controls for power or thrust on the basis of pressure altitude and air temperature; establishment of optimum cruising speed by means of density altitude which depends upon the two factors last mentioned; a ir navigation conducted to take account of pressure pattern flying, that is, by cruising on minimum time routes, determined with the aid of the pressure aititude, air temperature and other factors.

Pressure altimeters contain an internal mechanism which is essentially an aneroid barometer calibrated in accordance with the pressure - altitude relationship of the standard atmosphere. The pointers of the typical altimeter are actuated by changes of pressure exerted on the aneroid element. Consequently the pointers show deflections with respect to the base of the internal mechanism as the ambient pressure varies. This mechanism includes suitable cams, gears, levers, and other devices designed for a special purpose. The primary function is to permit the calibration on a uniform 
scale of pressure altitude when the instrument is set on the standard altimeter setting of 29.921 inches of mercury (101.31 $\mathrm{kPa}$. That is, with this setting, the pointer on a properly calibrated, perfect altimeter should indicate altitude corresponding to the ambient pressure, in accord with the standard atmosphere relationship. The mechanism must permit this relationship to hold despite the fact that uniform steps of increasing altitude correspond to gradually decreasing, nonuniform steps of pressure. In addition to the altimeter proper we have on board the pitot-static probe and the lines connecting it with the altimeter. Modern altimeters are usually provided with an electrical readout and digitizer, and are connected to a transponder for transmission of data to the flight controller on the ground. Two or three independent altimeter systems are found on most commercial aircraft.

of the four major purposes for which altimeters are required, vertical separation and vertical clearance of terrain seem to be the most critical applications. During take-off and landing most commercial aircraft are controlled by ground-based radar beacons and on-board radio altimeters (up to 1500 feet $(454 \mathrm{~m}), 2900 \mathrm{ft}(884 \mathrm{~m})$ on 747$)$ and the miscellaneous operations do not require comparable accuracy.

An error computation and reasonable estimates for the vertical separation of aircraft are difficult, if not impossible, to obtain. Several experts in the field, as for example Dr. DuFeu (personal communication) of Smith Aviation in Cheltenham, England, believe that the uncertainties in the vertical separation of aircraft often approach the separation presently used, i.e. $1000 \mathrm{ft}(300 \mathrm{~m})$ at altitudes up to $29,000 \mathrm{ft}$ $(8800 \mathrm{~m})$ and $2000 \mathrm{ft}(600 \mathrm{~m})$ above that.

Some representative data may be taken from a report of the ICAO Panel on Vertical Separation of Aircraft:

"Consider the case of two aircraft assigned different cruising altitudes or flight levels where normally one will pass over the other with an indicated vertical separation of $1000 \mathrm{ft}(300 \mathrm{~m})$; for example one aircraft at an indicated altitude of 5,000 ft (1500 m), the other perhaps opposite bound at an indicated altitude of $6,000 \mathrm{ft}(1800 \mathrm{~m})$. The ICAO Panel mentioned above found that a loss of vertical separation of $546 \mathrm{ft}(166 \mathrm{~m})$ is likely to be equaled or exceeded 3 times out of 1000 between aircraft passing on headings which normally require a $1000 \mathrm{ft}$ (300 $\mathrm{m})$ vertical separation provided that a constant, standard setting of 29.92 inches of mercury (101.31 kPa) is employed for the setting of the altimeters of both aircraft. The actual vertical separation of these planes would then be 454 feet $(138 \mathrm{~m})$. A further substantial reduction in the vertical separation may result if the two aircraft come from different airports and have markedly different altimeter settings (QNH). Thus, if the higher of the two aircraft employs a QNH value which is, say, 0.38 inches of mercury $(1.29 \mathrm{kPa})$ greater than that employed by the lower craft, the vertical separation will be reduced by another $350 \mathrm{ft}$ (170 m)."

"The question arises whether one should assume the most probable values of errors for the purpose of providing safe conduct of an airplane, or whether it would be more appropriate to use extreme values. Since the purpose of most aviation operation is the accomplishment of individual missions, it appears best to assume a definite probability of the occurrence of extreme errors. A careful distinction must be made between mean tolerances pertaining to errors as derived from statistical probabilities based on the behavior of large numbers of altimeters, aircraft etc. and the actual largest possible errors that could affect adversely the operation of the particular aircraft during a given flight. Since the crew and the passengers are more immediately concerned with the latter than the former, they will naturally consider it essential to give forethought to the contingencies and deem it discreet to allow for the chance that the errors may combine sometimes with the most adverse sign to a maximum degree."

Without going into more details we shall mention that errors of similar magnitude as those discussed for the instrument must also be expected for the static pressure system. Static system errors can be and are compensated automatically on many aircraft and consequently only the standard deviation of the errors needs to be considered for a total uncertainty determination.

\section{IMPACT, STATUS AND TRENDS OF THE MEASUREMENT SYSTEM.}

\subsection{Impact of the Measurements}

\subsubsection{Functional, Technological and Scientific Applications.}

Pressure is an important parameter in most manufacturing processes and must therefore be measured for control or optimization. Without such pressure measurements certain processes could not be used at all (leaktesting of radiators, can tops), others could not be optimized (power plants, refining, jet engines). Pressure is used to determine flow in pipelines (also for the detection of leaks). In the semiconductor 
industry partial pressures of the residual gases present during an evaporation process strongly influence the yield of the process.

Safety is an important reason for pressure measurements. Examples are measurements at numerous points in nuclear reactors, aircraft altimeter, cabin oxygen gages and automobile tires.

Scientific applications are primarily in the equation of state of fluids and solids, gasthermometry, oceanography and meteorology.

Military applications include the operation of aircraft, missiles and submarines to name only a few more critical areas.

\subsubsection{Economic Impacts -- Costs and Benefits}

Estimates for the cost of measurements come from three sources (a) our own estimate of cost for equipping and operating an industrial pressure standards laboratory excluding airlines and makers of aircraft; (b) information provided by calibration laboratories; (c) annual production volume of pressure and vacuum gages.

(a) Table 10 attempts to give an estimate of the cost of operating a small pressure standards laboratory sufficient for a large industrial plant or a small to medium size maker of pressure gages and transducers. The cost per 1aboratory is $\$ 43,000$ annually. With a total of about 250 makers of pressure gages and transducers this adds up to $\$ 10$ million. Naturally the cost of operating a calibration laboratory for an airline, aircraft manufacturer or maker of pressure standards is a multiple of the amount shown in Table 10 .

Table 10. Estimated Cost of Operating A Sma11 Secondary Pressure Standards Laboratory

\section{Capital Investments}

Pressure Standards

Transfer Standards

Auxiliary pressure equipment

General purpose equipment,

furniture

Amortized capital cost/year

Annual Operating Expenses

Salary for one person

Overhead

Capital cost

Operating funds, computer etc.

Total operating expenses \begin{tabular}{r}
16,000 \\
6,000 \\
3,000 \\
5,000 \\
\hline 30,000 \\
3,000
\end{tabular}

20,000

16,000

3,000

4,000

$\$ 43,000$ (b) During the Delphi study on vacuum calibrations, thirteen vacuum standards laboratories reported an estimated annual operating cost of $\$ 134,000$ per laboratory (average).

(c) The annual production volume for pressure and vacuum gages, SIC codes 38211 $46 / 47$, and 3821331 was $\$ 25.4$ million(1963). This is only a small part of the total production of pressure measuring devices (see also 4.3.1) many of which are not separately 1 isted.

These are examples for the cost of pressure measurements in the first and second echelons below NBS. The cost of pressure measuring devices in lower layers is much larger as shown in 4.3.1, and so are the operating costs. The manager of a nuclear (BWR) plant estimates that his plant spends $\$ 25,000$ annually just to investigate and report setpoint drift, mostly in pressure switches. There are about 100 such switches in each plant with a total acquisition cost of $\$ 60,000$.

One of the prime benefits derived from pressure measurements is safety. If accurate altimeter calibrations derived from NBS standards can prevent one crash or collision of a passenger airplane, the attendant savings can pay for the Pressure and Vacuum Section for 30 years or more.

\subsubsection{Social, Human, Person-on-the-Street Impacts}

All of us who travel by plane, car, railroad or ship are indirectly affected by pressure measurements required to operate or control these vehicles. $0 i 1$ and gas furnaces and airconditioners are controlled with pressure switches, so are pressure cookers.

A striking example for the savings that can accrue when each car owner keeps his tires properly inflated (to within $7 \mathrm{kPa}$ or 1 psi) goes as follows:

One out of every four cars has seriously underinflated tires. Proper tire inflation can improve gas mileage by 1 mile/gallon. Average gas mileage in the U.S. is 13.7 miles/gallon. Annual gasoline consumption in 1973 was 6.6 million barrels/day. Cost of gasoline is $\$ 0.51 /$ gallon. $100 \mathrm{million}$ cars are on the roads. If all car owners kept their tires properly inflated we could accrue a potential annual savings of $\$ 940$ millions or about $\$ 40$ for each car with underinflated tires. At the same time the life of the tires on these cars can be increased leading to another savings of about $\$ 7$ per car. Both for the individual and for the national economy these are significant benefits. The necessary expense 
for the individual is about $\$ 2.50$ for a tire gage, while the national measurement system should provide for the calibration of these gages. Neither airtowers nor hand held tire gages made available to the automobile driver at most gas stations are checked against adequate standardsunless they malfunction in a most conspicuous way. Airtowers were shown to be highly unreliable in an NBS report on this subject (NBS-TN 512). Hand-held tire gages are more reliable (Fig. 6) as long as they are protected from damage and contamination. The adequacy of calibration of these gages is obviously only part of the problem, but one that must be solved to reap economic benefits. Note that a more detailed calculation could include the benefits derived from the safer operation of a car with properly inflated tires.

Another pressure measurement that is very widely used by the generaly public is that of barometric pressure. Each radio and TV station disseminates the barometric pressure several times each day and numerous newspapers report it daily. It is used by many to satisfy their curiosity about tomorrow's weather, but it has economic impact for all who have to rely on weather forecasts such as gardeners, farmers, transportation, travellers, utilities etc.

\subsection{Status and Trends of the System}

The current status of the pressure measurement system within the range for which NBS provides calibrations is generally quite good. Primary standards available now agree with others in overlapping ranges and with standard in other national laboratories. They provide adequate accuracy for most applications and no major improvements are either needed now or anticipated for the near future.

At very high pressures, where no calibrations are now provided, a slow expansion is foreseen. This should be facilitated by the development of new transfer standards for very high pressures. New technologies in powder metallurgy, metal forming, coal gasification and synthesis of materials will require more and better measurements. Plans have been made to meet these requirements. Scientific requirements in equation of state, geophysics, explosive development, and related fields will be not be met.

In the range of atmospheric pressures and below into the low vacuum range, standards are either inadequate or nonexistent. Devel. opment of new standards is, however, rapidly progressing and this gap will be closed.

There are no national standards and no current plans for them for the medium and high vacuum ranges. This part of the mea- surement system quite clearly is out of control. There is nothing to provide uniformity of measurement throughout the system and it appears that a large industry depending critically on vacuum measurements is without measurement support. This situation has in fact existed for at 1east the 1ast 20 years with 1ittle effort on the part of the Bureau to substantially improve the situation. The industry seems to have resigned itself to the situation and tries to make the best of it. But most experts agree that it is severely handicapped. Difficulties arise in the transfer of technology, in providing uniform measurements, in specifying equipment and verifying such specifications and in measuring pumping speed. The lack of uniform measurements is especially felt in the sale and purchase of vacuum equipment, where it leads to inequities in the market place.

There are no facilities for dynamic calibrations nor for calibrations under extreme conditions of vibration, temperature, radiation or corrosion. Requests for dynamic calibrations come primarily from developers of steam turbines and engines, space vehicles and from researchers in the field of explosives. Some current research might eventually help to provide such services.

We feel that the part of the measurement system that deals with critical applications in air transportation and nuclear reactors is not completely under control. To ensure both accurate and uniform measurements of pressure measurement assurance programs (MAP) should be set up. Such measurement assurance programs could also benefit other areas of the measurement system where high accuracy is required at the point of use.

A further improvement of the accuracy at the point of use could be achieved by better error analysis in the lower parts of the calibration chains. Some work in this direction is now done in cooperation with NBS in two ASME committees. This will also require continued efforts towards better training of personnel in the lower echelon standards laboratories.

One problem that has not been systematically addressed by anybody is the performance of transfer standards, particularly transducers, used extensively in the lower echelons of the system. Unless reliable data on the long term performance characteristics of transducers and gages are available it will not be possible to estimate errors propagated in the system nor will it be possible to use these devices in MAPs.

With the rapid expansion of automatic process control and with increasing desire to reduce personnel cost the use of transducers will undoubtedly expand quite rapidly. The characterization and an economic calibration service will therefore gain in 
importance in the future.

Metrication does not seem to present a serious problem in the upper parts of the system. NBS has for several years written all calibration reports in the S.I. system and we have rarely had any inquiries about conversions. The question of optimal metric ranges for gages and transducers is now under study in committees. Several manufacturers already offer metric scales and calibrations.

\section{SURVEY OF NBS SERVICES}

\subsection{The Past}

A Pressure and Vacuum Section was formed at NBS in 1960. In 1965 it was divided into a Pressure Section and a Vacuum Section, which were then reunited in 1971. Finally the vacuum part of the section was abolished in 1973. Since its inception the Pressure Section has supported the highest echelons of the calibration hierarchy and has, to some extent, neglected the bulk of the system. It has also in the past neglected the systematic development of standards particularly in the manometric ranges. Consequently there has been a great need in recent years to bring the Section's standards up to the state of the art. The neglect of the manometric range has caused the airtransport industry to set up its own standards at great expense and without the benefit of being firmly integrated into the national measurement system. The Vacuum Section began to develop standards in 1965 but never delivered any significant calibration service except to a few top echelon laboratories over a limited range.

Among the major accomplishments of NBS in the past is the development of the controlled clearance piston gage principle and the refinements in the art of using these gages. Controlled clearance piston gages are now used as primary standards at NBS and in several other National Standards Laboratories.

\subsection{The Present - Scope of NBS Services}

\subsubsection{Description of M!BS Services}

\section{(a) Calibration}

The NBS Pressure Section provides calibrations over the range from $2 \times 10^{3}$ to $4 \times 10^{8} \mathrm{~Pa}(0.3$ to to $60,000 \mathrm{psi}),(\mathrm{Fig} .6)$. These calibrations are performed by comparing transfer standards maintained by NBS. Characteristic data obtained from these comparisons are compiled in a detailed report for the customer. The report also contains ample information on the conduct of the test as well as estimates of systematic uncertainty and random errors.

There is no restriction on the types of instruments that NBS will accept for calibration. The time required for most instruments is eight weeks and the cost is approximately $\$ 500$ per range. The calibration of controlled clearance piston gages takes three to four months and the cost averages about $\$ 4000$.

\section{(b) Data Evaluation}

Laboratories wishing to use NBS programs and codes for the evaluation of their own data can do so by submitting these data on NBS work sheets.' The data will be evaluated and returned within about 4 work days. The cost is about $\$ 100$ per standard set. This provides the user with the best possible evaluation of his data, including the statistical analysis.

\section{(c) Measurement Assurance}

NBS is prepared to set up measurement assurance programs for a wide range of pressures. This would entail shipping a calibrated transfer standard from NBS to the customer's point of use. It would there be calibrated against the customers standard and returned to NBS. The customer will then receive a report with an evaluation of his measurement. Frequency, turn-around time and cost will be determined individually for each application.

\section{(d) Laboratory Evaluation}

In urgent and critical cases NBS will send a team to a standards laboratory to evaluate standards and procedures and to calibrate them against an NBS transfer standard in situ. This has the advantage that several plant standards can be compared and that qualified NBS personnel are at hand to operate the transfer standard. The cost of this service is quite high and it should therefore be used only under urgent conditions.

\section{(e) Training}

Calibration services are supplemented with training courses for industrial standards laboratory personnel. These courses take two days at a cost of $\$ 105$. The number of participants is limited so that there is. time for everybody to get hands-on experience. Two morning sessions are devoted to theory of piston gages, design, data collection, analysis and interpretation of results, calibration of transducers and a short review of current NBS activities in this field. The afternoons are spent in the laboratory.

Such courses also can be and have been held outside NBS. 


\section{(f) Transducer Evaluation}

A transducer evaluation service is now available from NBS. Under this program manufacturers or users can submit pressure transducers to NBS for an extended performance test. Sensitivity, resolution dependence on environmental and operational parameters, drift, hysteresis and long term stability during thousands of pressure cycles are determined. The user will be provided with an extensive report containing all the data generated during the test and their analyses.

The submitter is urged to make these data available to others upon request. The purpose is to generate reliable data for transducers to facilitate their introduction into more critical areas of the measurement system and to provide equity in the market place. The cost will be about $\$ 1500$ for the first and $\$ 400$ for any other transducer of the same type and range. The test will last for 6 to 8 months.

\section{(g) Research and Development}

The National Bureau of Standards will undertake specific research and development programs within its mission for government agencies, and other appropriate sponsors. These may be the development of new principles of measurements, generation of specific data, writing of reports etc. for which NBS has particular expertise.

\section{(h) Publications}

NBS provides information on topics related to the national measurement system in the form of talks, seminars, reports and publications. New technical reports are now in preparation on measurements with piston gages and manometers and on numerical analysis of data and error computation.

Such publications present also the results of development and research at NBS as, for example, data on fixed points, phase lines and equations of state.

\section{(i) Consultations}

Consultations are an important part of the services rendered by NBS. They are generally free of charge. Consultations can be made by visit to NBS or in the quarters of another organization, by letter and by telephone. They cover all matters in which NBS can provide assistance and may range on one day from the operation of an Italian cappuccino machine to high-frequency dynamic pressure calibrations. In these consultations information flows in both directions.

Cooperation of NBS experts in professional societies could be listed under consultations as well. Members of the staff are actively working in a number of orqanizations, a few of which are listed in tabile 11.

Table 11. Committee Memberships

(Pressure Measurements)

ASME Committee on Pressure Gages

ASME Research Committee on Press. Technology. ASME Power Test Code Committee

ASME Joint Committee for High Press. Technol. ISA Committee on Manometry

The general position of NBS in the InputOutput Transactions Matrix of Table VIII was already discussed in section 2.5. Some additional information is shown in figs. 7 and 8 . Fig. 7 identifies schematically the types of input received and outputs delivered by NBS, while fig. 8 shows the sources of the input and the recipients of the output.

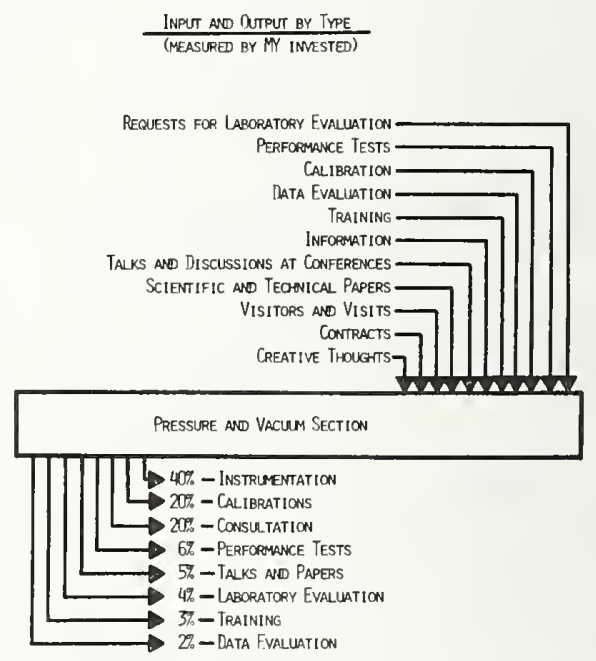

Figure 7. Input/Output by Tvpe 


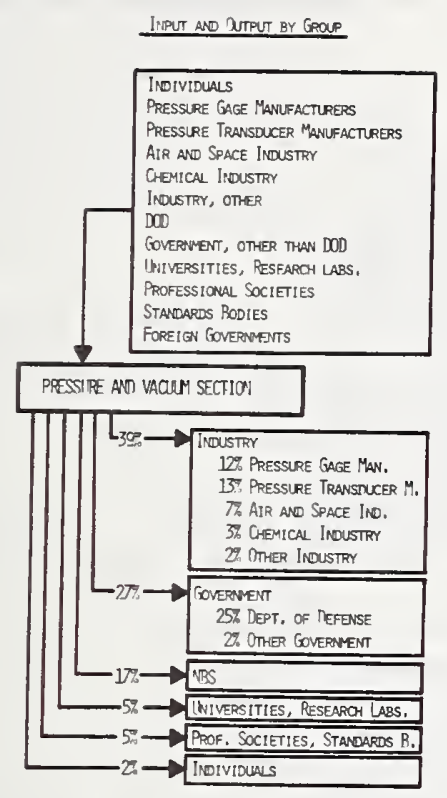

Figure 8. Input/Output by Group

\subsubsection{Users of NBS Services}

Table 12 contains a list of users of NBS calibrations services, which confirms our earlier statements about the wide-spread application of pressure in almost all industries. However, one must keep in mind that as a rule only the upper echelons of the calibration hierarchy send standards to NBS for calibration. The manufacturers of pressure gages listed under 1.) in Table 12 are in this upper echelon and carry a much greater weight in the system than their number in the table indicates.

\subsubsection{Alternative Sources}

For pressures above atmospheric very few primary standards outside NBS are accessible to the public. Most of them are placed in laboratories of the Department of Defense, which do not provide calibrations for the public. In the manometric range a large number of primary standards can be fou $d$, some of which are available for dissemination of calibrations. Several of the labo atories listed in table 8 provide this service.

$\mathrm{No}$ other source can provide calibrations of the same or lower uncertainty than NBS. In principle, other laboratories could set up primary pressure standards and provide the service, but the calibration and further development of these standards requires technical back-up services, for which NBS has unique expertise and facilities. It is therefore not likely that commercially operated, primary laboratories would be able to provide adequate services at economic cost.

\subsubsection{Funding Sources for NBS Services}

The development and maintenance of NBS facilities are conducted with NBS funds with considerable other agency funds for special development programs.

The cost of performing calibration services is charged to the customer. 
Table 12. Listing of users of NBS pressure and vacuum calibration services

1.) Manufacturers of pressure and vacuum gages

Chandler Engineering Co.

Ametek - Mansfield \& Green

Pneumercator Co.

Seegers Instrument Corp.

Texas Instruments, Inc.

Gi1more Industries, Inc.

Ruska Instrument Corp.

Exactel Instrument Co.

Ideal - Aerosmith

H.J. Green Insts., Inc.

Amtkor

2.) $D O D$

Naval Ship Research \& Development

Army Map Service

Dept. of the Navy

Naval Ordnance System

David Taylor Model Basic (Navy)

Dayton Air Force Station

U.S. Naval Air Station

Naval Air Station

Benicia Arsenal (Dept. of Army)

Eastern Standards Lab

Frankford Arsenal (Dept. of Army)

Redstone Arsenal (Dept. of Army)

Naval Ordnance Laboratory

U.S. Army Procurement Office

NASA

Pratt \& Whitney

Tooele Army Depot

Newark Air Force Station

Naval Air Station

Harry Diamond Lab

Picatinny Arsenal

3.) NASA

NASA - Langley

NASA - Lewis

NASA - Houston

NASA - Goddard

NASA - MSC

NASA - Cape Kennedy

NASA - El1ington

NASA - White Sands

4.) Government Agencies (except DOD, NASA)

F.A.A.

Sandia Corp.

Tennessee Valley Authority

5.) Chemical Industry

Union Carbide Corp.

01 in Mathieson Chemical Corp.

Monsanto Research Corp.

Thiokol Chemical Corp.

Du'Pont de Nemours \& Co.

Manard Molasses Co.

Thiokol Chemical Corp.
Tulsa, OK

Solon, $\mathrm{OH}$

New York, N.Y.

Barrington, IL

Houston, TX

$\mathrm{Cl}$ evel and, $\mathrm{OH}$

Houston, TX

Mountain View, CA

Cheyenne, WY

Westbury, N.Y.

Brooklyn, N.Y.

Langley, VA

$\mathrm{Clevel}$ and, $\mathrm{OH}$

Houston, TX

Greenbel t, MD.

Huntsville, AL

Cocoa Beach, FL

Ellington, AFB, TX

Las Cruces, NM

Atlantic City, N.J.

Albuquerque, NM

Chattanooga, TN

East Alton, IL

Miamisburg, $\mathrm{OH}$

Elkton, MD

Gibbstown, NJ

Gretna, LA

Brigham City, UT 
Du Pont de Nemours \& Co.

Eldorado Terminals Corp.

Refinery Supply Co.

Pacific Molasses Co.

Hercules Powder Co., Inc.

Union Carbide

Sucrest Corp.

National Molasses Co.

6.) Utilities

Detroit Edison Co.

Ohio Fuel Gas Co.

United Fuel Gas Co.

7.) Air and Space Industry

Hughes Aircraft

McDonne11 - Douglas Astronautics Co.

North American Rockwell Corp.

MCDonnel Aircraft Corp.

Aerojet - General Corp.

Rocketdyne - North America Avia.

Martin Marietta Corp.

Douglas Aircraft Co., Inc.

Genera1 Dynamics Corp.

Goodyear Aircraft, Corp.

Rocketdyne - North Amer. Avia.

Hughes Aircraft, Co.

Republic Aviation Corp.

Boeing Company

Lockheed Aircraft Corp.

Pratt \& Whitney Aircraft

Avro, Inc.

General Dynamics / Astronautics

Lockheed Aircraft Corp.

Lockheed Aircraft Corp.

North American Aviation

United Air Lines

North American Aviation

Martin - Marietta Corp.

North American Rockwe1 1

8.) Industry (except Chemical, Utilities, Air and Space)

Varian Assoc.

Westinghouse Electric

Raytheon Co.

Chicago Bridge \& Iron Co.

Intercontinental Dynamics Corp.

General Electric

ILC Industries Inc.

E-A Industrial Corp.

Industrial Instruments, Inc.

Firestone Tire \& Rubber Co.

Bendix Corporation

Wright Instruments, Inc.

Leeds and Northrup Co.

AVCO Research \& Development

(A11ison Div.) General Motors

General Electric Co.

Blout Brothers Construction Co.

General Electric Co.

Cincinnati Milling Mach., Co.

Bendix Corporation
Aiken, SC

Bayonne, NJ

Tulsa, OK

Houston, TX

Radford, VA

Oak Ridge, TN

New York, N.Y.

Baltimore, Md.

Detroit, MI

Columbus, $\mathrm{OH}$

Charleston, W. VA.

Anaheim, CA

St. Louis, MO

Sacramento, CA

Canoga Park, CA

Denver, CO

Santa Monica, CA

Fort Worth, TX

Akron, $\mathrm{OH}$

Neoshe, MO

Culver City, CA

Farmingdale, N.Y.

Seattle, WA

Marietta, Georgia

West Palm Beach, FL

Arnold Air Force Station, TN

San Diego, CA

Sunnyvale, CA

New York, N.Y.

Downey, CA

San Francisco, CA

Tulsa, OK

Baltimore, MD

Downey, CA

Baltimore, MD

Andover, MA

New Castle, DE

Englewood, N.J.

Bay St. Louis, MS

Dover, DE

Chamblee, GA

Cleveland, $\mathrm{OH}$

Pottstown, PA

New York, N.Y.

Vesta1, N.Y.

Philadelphia, PA

Wilmington, MA

Indianapolis, IN

King of Prussia, PA

Montgomery, AL

Cincinnati, $\mathrm{OH}$

Cincinnati, $\mathrm{OH}$

Baltimore, MD 
Research Manufacturing Co.

Muirhead Instruments Inc.

Bendix Corp.

Astra Corp.

Brown Boveri Corp.

Bendix Corp.

General El ectric

Marquardt Corp.

Melpar

General Electric Co.

Metal Bellows Corp.

Hildebrant Engineering Co.

Curtiss-Wright

Carrier Corp.

Litton Systems, Inc.

IBM

Hercules, Inc.

Rosemont Eng. Co.

9.) Universities and Research Labs

Carnegie-Mellon University

Argonne National Laboratory

Brookhaven National Lab.

Battelle Memorial Institute

University of Michigan

University of California

University of $0 \mathrm{klahoma}$

Lawrence Radiation Lab.

10.) Foreign Organizations

Physik - Institut der Univ. Zurich Australian Government
Phoenix, AZ

Mountainside, N.J.

Teterboro, N.J.

Hatboro, PA

New York, N.Y.

Kansas City, MO.

Ballston Spa., N.Y.

Ogden, UT

Falls Church, VA

Schenectady, N.Y.

Sharon, MA

Houston, TX

Woodridge, N.J.

Syracuse, N.J.

Woodland Hills, CA

San Jose, CA

Cumberland, MD

Eden Prairie, MN

Pittsburgh, PA

Argonne, IL

Long Island, N.Y.

Columbus, $\mathrm{OH}$

Ann Arbor, MI

Los Alamos, N.M.

Norman, OK

Berkeley, CA

Zurich, Switzerland Australia 


\subsection{Impact of NBS Services}

\subsubsection{Economic Impact of Major User Classes}

The manufacturers of piston gages benefit most immediately from pressure measurements disseminated from NBS standards. They, in turn, provide the transducer and gage manufacturers with pressure calibrations. From this second level a large variety of important industries is affected as outlined in previous sections of this report. Table 13 lists the annual production of a number of products, which benefit from NBS services. The large variety of these products, which require pressure for their operation, for' their manufacture or for safety reasons, indicates the impact of pressure measurements on economy and society.

\subsubsection{Pay-off from Changes in NBS Services}

Most recent changes in NBS services for the national measurement system for pressure have been gradual improvements in quality (accuracy, detailed information, training) or range. These changes were aimed at satisfying requests from the manufacturers of gages and transducers or other users of our services.

A rather important change was the elimination of the vacuum calibration service. This service had never developed a high use rate, but extensive consultations were given to industry on topics related to vacuum measurements. Discontinuing this service left the vacuum industry without any type of national standard or central authority.

\subsection{Evaluation of NBS Program}

For the pressure range $2 \times 10^{3} \mathrm{~Pa}(.2 \mathrm{psi})$ to $4 \times 10^{8} \mathrm{~Pa}(60,000 \mathrm{psi})$ NBS has adequate primary and working standards and a good dissemination program to the next echelons in the calibration hierarchy. This is backed by training, data evaluation, laboratory evaluation, by writing manuals and technical notes on state of the art measurements and by extensive consultations. There is close cooperation between NBS and the industries concerned. Adequate $\mathrm{pl}$ ans are in effect for the expansion of the range and the improvement of the standards.

The adequacy of present services is measured by comparing the services delivered with the requests received. These requests come directly as purchase orders for calibrations, as inquiries or they result from our frequent personal contacts in meetings and training courses.
Table 13. Annual production volume of some industries benefiting from NBS services

SIC-code Industry Ann. Prod Year in $M \$$

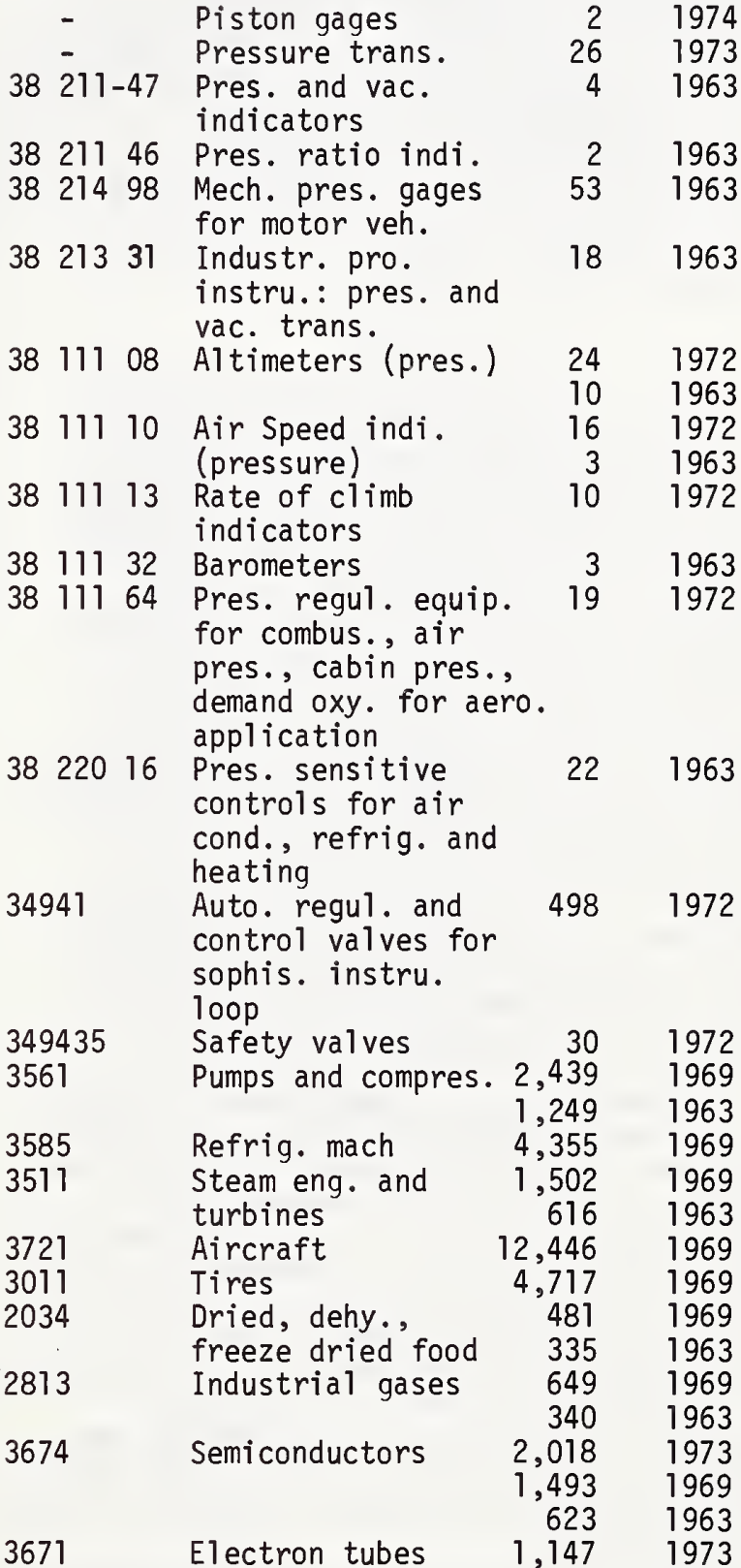

Data from Bureau of Census and McGraw-Hill Market Forecast. 
If NBS were to discontinue its pressure calibration services, then the industry would find itself in the position of either setting up their own primary standards $1 a b-$ oratories or of gradually moving away from uniform measurements throughout the country with chaotic consequences for the gage and transducer industries and all of their customers. The maintenance of safety would become impossible. Setting up good primary pressure standards is not a feasible commercial venture as it requires the sophisticated metrology back-up that only a national laboratory can provide and it requires systematic research and development of new or improved methods.

\subsection{The Future}

While present services are adequate from $2 \times 10^{3}$ to $4 \times 10^{8} \mathrm{~Pa}$ except for the manometric range from $10^{4}$ to $10^{5} \mathrm{~Pa}$, there are no such services above and below this range. Presently there is very definite and urgent need for calibration services at lower pressures and a need for services at higher pressures is anticipated for the future.

Measurements in the range from $2 \times 10^{3}$ $\mathrm{Pa}$ down to about $10^{-2} \mathrm{~Pa}$ are now urgently needed for the calibration of flight control instrumentation, for safety systems on nuclear reactors, and for a large variety of industrial applications. These needs were identified and plans to provide the service were made. It is anticipated that a primary standard covering the upper part of this range will be in operation late in FY 76 and that the rest of the range will be covered by a new standard late in FY 77

Measurements in the range above $4 \times 10^{8} \mathrm{~Pa}$ will be needed in the future by the emerging new technology for high pressure forming and extrusion. Again, plans have been made to provide these services in the near future. These and the plans for expansion of services into the vacuum range have been discussed with the Division Advisory Panel and have the strong support of most members of the panel.

Training of personnel in industrial standards laboratories is a continuing need. Courses offered by NBS will be extended to include manometry and several manuals will be issued shortly.

Major new needs arise from the increased application of pressure transducers, which are rarely well characterized. It is therefore difficult to choose the right types and to estimate the propagation of errors. Great inequities exist in the market place. NBS has therefore developed a transducer evaluation program, which will be offered as a service beginning in FY 76. At the same time a low-cost calibration service for transducers and gages will be offered.

A study of the needs for vacuum measurements is still under way and a decision on resumption of vacuum work will be made later.

\section{Summary and Conclusions}

The state of the national measurement system for pressure in the range where NBS presently provides calibrations and related services is satisfactory. Needs for expansion of the range have been identified and most of these needs will be satisfied in the near future.

Rapid changes in the needs of the system are generated by the increased use of transducers to transfer measurements, and plans are being implemented at NBS to provide al1 necessary services.

No preparations have been made to establish primary vacuum standards at NBS. A Delphi study on vacuum calibration needs is under way. A management decision must be made, when the study is completed. 


\section{APPENDIX A. METHODOLOGY OF THE STUDY}

The study was conducted in five parts:

(1) Investigation of two calibration chains to the point of end use,

(2) Solicitation of written comments on needs for measurements at very high pressures,

(3) Delphi study for vacuum measurements,

(4) Survey of existing literature, particularly the applicable standards,

(5) Personat interviews.

Table 14 contains a list of persons contacted during this study. It does not include the participants in the Delphi study, who wi 11 remain anonymous. We are indebted to 271 of them, listed and unlisted, for their often considerable effort to help us in this assessment.

In the investigation of the calibration chains we attempted to gain insight into the details of the dissemination: the instruments used, the personnel and their training, numerical methods and error estimation etc. This part of the investigation caused us to begin training programs and to devote time to write a manual on numerical evaluation methods. It also showed the need for measurement assurance and for a reduction in the length of the calibration chains.

Comments on the need for high pressure calibrations were invited from a number of researchers and workers in this field. The names of those contacted are contained in table 14. The letters provided information about the pressure range, required accuracy and applications.

The Delphi study on vacuum calibrations is still under way. It was begun with a letter to a small number of experts asking for rather detailed answers to a large number of questions ranging from the presently used source of calibrations to problems foreseen in the future. This was followed by the dissemination of the questionnaire shown in Figs. 9 and 10 . More than one hundred of the questionnaires have been received and evaluated. An example of part of this evaluation is shown in Fig. 17. It shows under the same key numbers as the original form the lower and upper quartiles, the median and the experts estimates as to when a certain measurement is required for the two application areas. We are presently working on improving the consensus. The study will be published separately.

The literature was searched for information pertinent to this study. Little important information beyond production numbers and general statements was found. We also examined existing standards to find whether they contained adequate information on methods, instrumentation and numerical evaluation to achieve their stated purpose. This is generally not the case, and we are encouraging and helping to make the necessary improvements.

Visits, telephone conversations, letters, conferences, and training courses were used to obta in additional, more detailed or confirming information. This process is continuing and the flow of information (both ways) is probably the most valuable effect of this study.

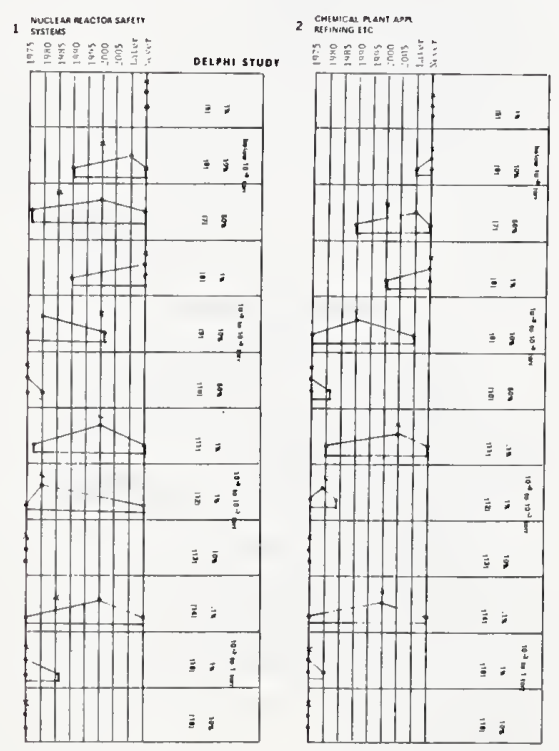

Figure 11. Delphi Evaluation 
Andeen C., Case Western Reserve Univ.

Andrews W., Bureau of Mines

Aust R.B., Eastman Kodak

Austin C., IBM

Babb, S.E., University of Ok1ahoma

Balkosky G., Detection Technology

Ballingall J.M., Varian Inc.

Bartz T., Lockheed

Benson J., Haystings-Raydist

Blevinn G. Brunswick, Corp.

Bone A., RAF. Great Britain

Brecht M., United Airlines

Brown G.V., NASA Lewis Research Center

Bundy F.P., G.E.

Burris L., Argonne Nat. Lab.

Carbaja B., Texas Instruments

Carrozzo T., Detection Technologv

Cerbs D., Detection Technology

Charton J., General Foods

Christoe C.W., Feltman Research Lab.

Clapham P., N.P.L. Great Britain

Cohrs G., Boeing

Costantino M.S., U.S. Military Academy

Council T., FAA

Craig 0., USN, Air Systems Command

Damre1 J.B., Texas Instruments

Daniels W.B., University of Delaware

Drickamer H.G., University of Illinois

Dufeu A.N., Smiths Aviation

Duva11 G.E., Washington State University

Edwards H.B., NASA Langley

Fabbroni J., Kollsman Instruments

Farrish B., United Airlines

Favel1 G., Wallace and Tiernan

Feierabend R., Gilmore Industries

Frack R.B., FAA

Frisbie D., Varian Inc.

Fritz I.J., Sandia Lah.

Friz G., Wallace and Tiernan

Fruit J., Mensor Corp.

Fulton W.C., NASA Houston

Gray H.L., NASA Langley

Hablania M.H., Varian

Hale D., Wallace and Tiernan

Hal1 H.T., Brigham Young University

Hardison H.V., DuPont Corp.

Harra D., Varian Inc.

Harris H., EXXON

Hill E., Varian

Hi11 W.W., Westinghouse

Huntress A., DOW Corning

Irwin J.W., Boeing

Jamieson J.C., University of Chicago

Jayaraman A., Bell Telephone Lab.

Johnson A., Dresser Industries

Jones D., Boeing

Joslyn D.E., Viatran Corp.

Kafalas J.A., M.I.T.

Kahn E.H., Kollsman Instrument Corp.

Kohatsu I., U.S. Army Materials Research Center

Kopp M., Validyne Corp.

Krause E.J., DOC, Office of International Trade

Kremerskotter F., United Airlines

Kullman G., USN, Western Standards Lab.

Lafferty J.M., G.E.

Lange W.J., Westinghouse

Lauer A., Varian Inc.

Layman W., United Airlines
Lazarus D., University Illinois

Lee A., Boeing

Lewis G.K., E.I. de Pon de Nemours

Liebenberg D.H., Los Alamos Scientific Lab.

Littmann A.J., Amthor Testing Instrument Co.

Lombardo J., High Vac. Equipment Corp.

LOW G.M., NASA HDQRT

Lunde A., Boeing

Lush W., Ideal Aerosmith

Matychuck D., Rosemont

Meyer H., United Airlines

Meyers D.E., Leybold-Heraeus

Miks C., Ruska Instruments

Musa R.S., Westinghouse

Nerken A., VEECO

New R., USAF Newark

01 son L., United Airlines

Osterstrom G., Sargent-Welch

Overacker $W$., Temescal Corp.

Patton P., Leybold

Patterson D., Boeing

Ralston K., Philadelphia Electric Company

Redhead P.A., N.R.C. Canada

Reed W., Republic Steel

Reesby C., Texas

Riley J., NASA Kennedy Space Center

Romana A.R., Kollsman Instrument Corp.

Rudolph J.F., FAA

Rush D., Varian Inc.

Russo F., Brunswick, Corp.

Samara G.A., Sandia Lab.

Sanford T.W., FAA

Scheve G., United Airlines

Schirber, J.E., Sandia Lab.

Schrager J., FAA

Schultz R., USN, Pomona

Smerke J.J., Philadelphia Electric Company

Smith C.S., University of North Carolina

Sobolewski R., Republic Steel

Southern R.L., A7legheny Ludlum

Spengler $C$., Boeing

Spetzler H., Sandia Lab.

Steffens B., EXXON

Strauss T., Wallace and Tiernan

Street H.B., U.S. Military Academy

Struisa F., G.E.

Stubblefield R.L., NASA HDQTR

Taylor W., Sandia, AEC

Tongas D., Boeing

Twigg W.P., Westinghouse

Vedam K., Penns. State University

Vissers D., Argonne Nat. Lab.

Waterman H., FAA

Wheeler W., Varian Inc.

Whitlock M., United Airlines

Wolfe R., MKS Instruments

Wolny R., Oak Ridge Nat. Lab.

Woolrich R., Ideal Aerosmith

Zielesch E., Ford Motor Company 


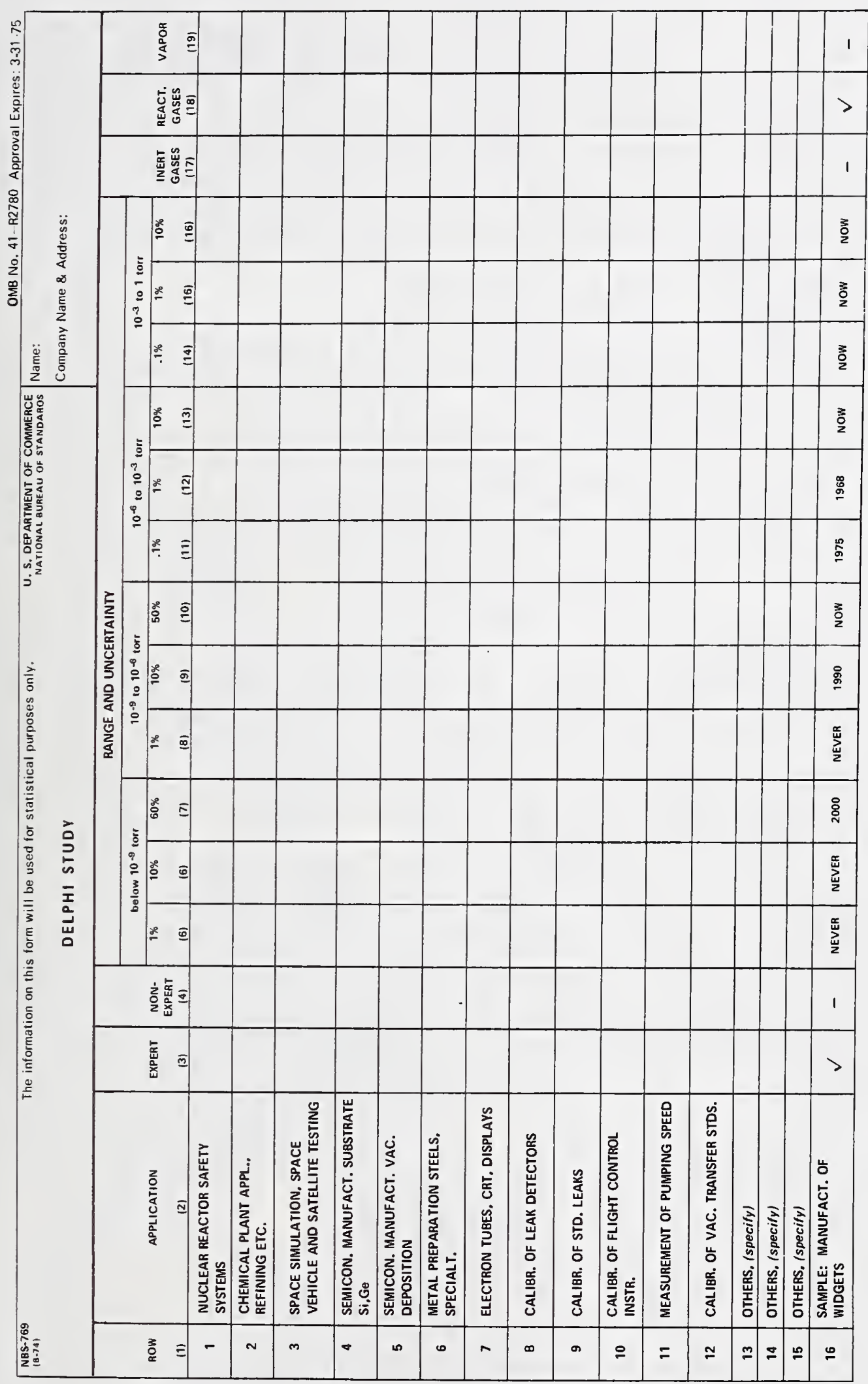

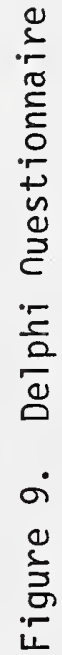


Dear Sir

In May of 1973 I asked a small number of experts in the field of vacuum for information on vacuum calibration practices and needs. The reason for this request for information was explained in a letter, a copy of which is included with today's letter. The response to our request exceeded our expectations both in the number of people responding as well as in the completeness of the information provided. We are very much indebted to all of you who contributed. We have studied the information and have designed from it the enclosed Delphi questionnaire. This is the first of two or possibly three communications which we shall use to establish consensus about the time at which certain vacuum measurements become critical, In any given application of vacuum in an industrial process there will come a time when an accuracy of, say, $1 \%$ in a certain range, for example $10^{-3}$ to $10^{-6}$ torr, must be reached to obtain optimum results. If the accuracy is not reached the measurement of vacuum becomes a technological barrier for the given process. We want to develop a best estimate for the dates at which certain accuracies in certain pressure ranges must be attained for a number of important processes or applications.

Our Delphi questionnaire lists several important applications of vacuum. For each process there is a choice of four vacuum ranges, and within each range there is a choice of three accuracies to be attained. We would like you to enter the year in which you think a given accuracy and range will be required for the processes listed. Let me use the manufacture of widgets (row 16) as an example. Widgets, according to Webster's, are unnamed articles considered for purposes of hypothetical example as the typical product of a company. In the Delphi questionnaire I identified myself as an expert on widgets by checking col. 3. I then selected the range $10^{-6}$ to $10^{-3}$ torr as the most important range for widget production, ano I know that as early as 1968 an accuracy of about $1 \%$ in this range would have been desirable for economic production. That is not to say that widgets were not made, but a better and more uniform product could have resulted. Sol entered "1968" in col.12. Of course, all of us who are familiar with widget production, know that improvements have been made.but that no later than 1975 an accuracy around .1\% in the same pressure range must be met to ensure economical production. Therefore, that year was entered in col. 11. Similarly I entered my estimates for the time when accurate measurements at much lower pressures will be needed. 1 also checked col. 18 to indicate that reactive gases are used in the process. Please attempt to fill in all columns as appropriate.

We would now ask you to consider the real industrial processes listed and to enter your best estimates.' After the questionnaires are returned we will determine the interquartile ranges and the median year for each application. The second Delphi round will include this information, thus allowing the respondents to revise their estimates in the light of the panel's earlier response.

We may have left out processes that you believe are important. Please use rows 13 to 15 to enter those. We may then ask others to give their best estimates for these additional applications.

Please identify yourself on the form so that I can contact you again about specific questions. The information provided by you will be kept confidential. Only myself, Dr. J. Seeds, Scientific Assistant to the Director, and Dr. H. Oser, Chief, Mathematical Analysis Section, will have access to the questionnaires. Only statistical data will be published. All participants in this Delphi study will receive a copy of our final report.

If you have any further questions, please, do not hesitate to call me on (301) 921-2121.

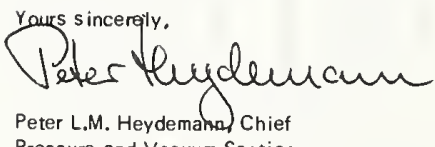

Pressure and Vacuum Section 